
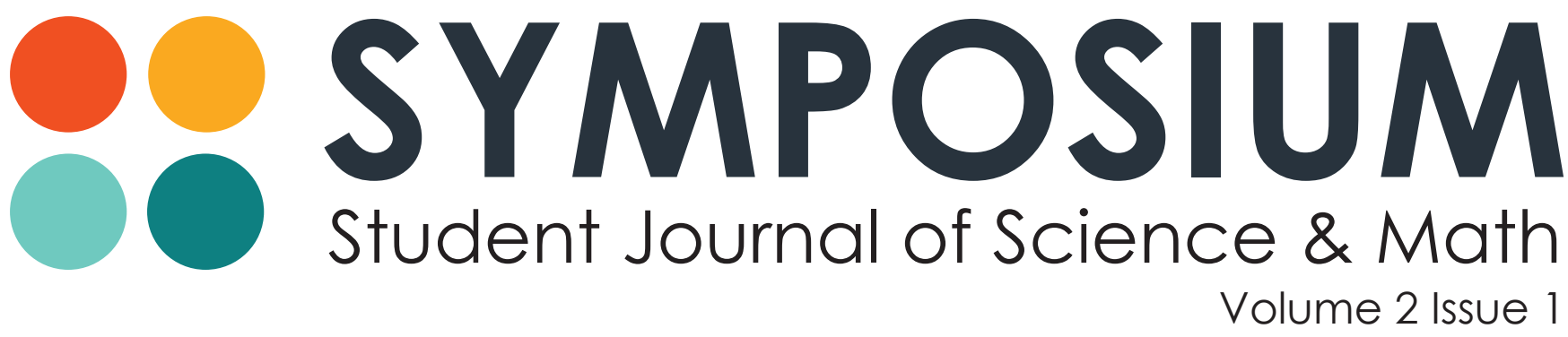


\section{PROTOCOLS FOR CLEANING AND ARTICULATING LARGE MAMMAL SKELETON}

A RESEARCH PROTOCOL

by Brandon Rowley

\section{Introduction}

This protocol will refer to Panthera tigris as an example for each cleaning method and articulation because that was the organism subject to this procedure. However, the processes and methods discussed here can be used as reference for any large mammal. The key is to make sure the skeleton is clean, which entails removing the meat from the bones, degreasing, and whitening. Once this is done, articulation can begin. The protocol is divided into three major sections: cleaning the skeleton, whitening and degreasing, and articulation. The cleaning section contains three contemporary methods for removing tissue. Each method can be performed independently to get the job done; however, we experimented with all three, so each process will be discussed.

\section{Section I: Cleaning the Skeleton}

\section{Boiling}

This technique is the most time-efficient, but has a much larger risk of error. Boiling will strip the bones of most fat and tissue within a couple of hours but requires careful watching. By nature, this procedure has the largest risk of error by having organic matter subject to $100^{\circ} \mathrm{C}$ for extended periods of time. However, it will effectively degrease as it strips the bone of tissue, and most of that tissue will simply fall off without further encouragement. Unfortunately, there is not a perfect science for how much time a bone should be boiled depending on its exact mass or volume. Bones of all sizes are durable enough to withstand boiling for at least a couple hours before they could fall apart, assuming they are 
in good condition (few to no cracks, breaks, or holes). Use caution when boiling the skull, however. Consider using the cold water maceration process for skulls. The skull of a tiger is articulated by 29 different bones connected with fine fissures, and can degrade rapidly. There are also paperthin bones called turbinates in the nasal cavity, which are also susceptible to rapid degradation. Boiling the skull may also cause the teeth to crack. Bones can be boiled in groups. Keep in mind that the water may take a while to begin boiling if the volume is large enough. If the intention is to boil the entire skeleton until all tissue is removed, the following protocol should be followed:

\section{Materials}

- Metal containers with appropriate volumes to fit bones-ideally several different sizes that fit the bones well

- Tongs

- Propane

- Barbecue lighter

- Latex gloves for handling bones and potentially raw meat

- Leather gloves for touching hot metal

- A hose or water source

- Copper wire

\section{Methods}

- Dissect the organism, removing all organs and as much tissue as possible from the skeleton.

- Thread the vertebrae together with copper wire to keep them in order in case they disarticulate unexpectedly. Thread the ribs together in order as well.

- Find a metal container large enough to fit in the entire bone. The container must have enough height to fit the bone, as well as around one-fourth of its overall length so you do not have to fill water to the brim of the container. We used propane connected to a large stove to bring the pot to a rolling boil. - Once the water begins to boil, fully submerge the bone and close the lid to the container. Be sure to have gloves sturdy enough to touch hot metal (we found gardening gloves sufficient).

- If the bones have sparse tissue or a thin layer of meat on them, start the boil for one hour and check every 20 minutes. If the bones have a considerable amount of meat one-inch thick or more (or an entire animal, for that matter), plan to boil for four hours minimum.

- Refill the container with water if enough evaporates to expose some of the bone.

- If you are worried about the structural integrity of the bone, you may use a pair of tongs to remove and inspect the bone every I5 minutes. For example, one of the scapulas of our tiger began developing a hole; after 15 minutes, it grew a bit larger, so we decided to remove it from the boiling process.

- Once all the meat has been removed from the bones, you may remove the bones from the water. 


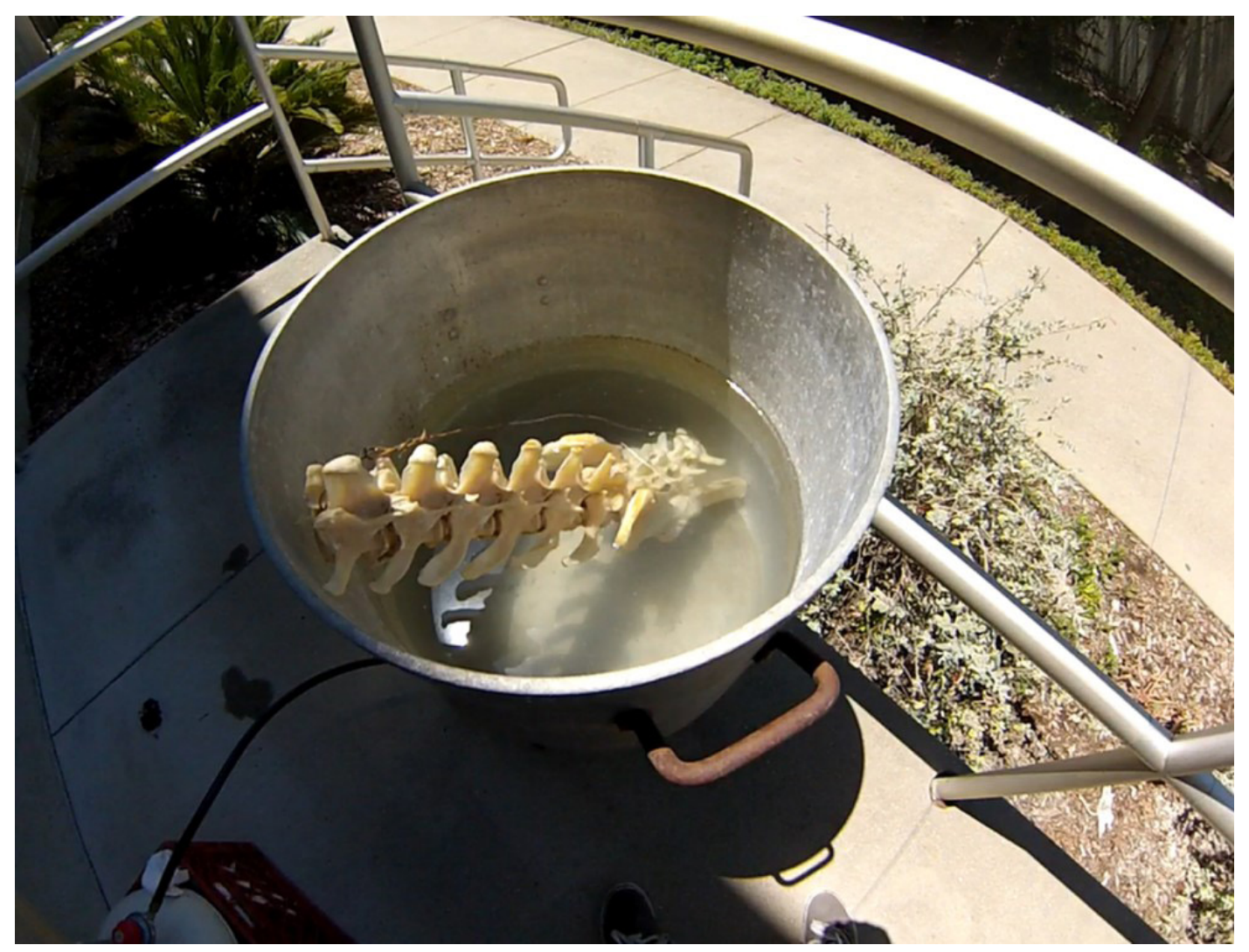

Figure I - Example of the boiling apparatus. The fuel tank can be seen on the bottom left with a connection to the stove. The photo is incorrect in that it should represent the spine fully submerged in water.

\section{Cold Water Maceration}

This requires less maintenance, has less risk for error, and has less time dedication per day, but takes the longest amount of time overall. All this procedure requires is enough tubs to fit the skeleton and enough water to cover the bones. Cold water maceration involves allowing the organism to sit in tap water for weeks at a time while microbes and bacteria from the surrounding environment begin to colonize the tubs and dispose of remaining tissue, essentially liquefying it. We recently ran an experiment with four mountain lion skulls, beginning the maceration process at different temperatures, and found the maintenance of water temperature to be insignificant to the progress of the maceration process. Room temperature is fine.

\section{Materials:}

- Plastic containers with lids

- Tap water

\section{Methods}

- Strip the organism of as much meat as possible in order to save time.

- Thread the vertebrae together with copper wire to keep them in order in case they disarticulate unexpectedly. Thread the ribs together in order as well. The copper wire should not rust during maceration; and even if it does, the stain can be removed easily during the whitening phase. 
- - Separate the organism in to distinct parts.

o Keep the feet as separate entities to avoid mix-up of smaller disarticulated bones.

o Individual legs

o Rear half of spine and pelvis (or equivalent)

o Front half of spine and atlas (or equivalent)

o Skull

o Tail, if present

- Fill containers with tap water. Each section of the organism should be assigned its own clearly labeled container.

- Place bones in containers and seal the lid. If no lids are available, simply check the water level weekly and refill if there has been too much evaporation.

- Decant heavy buildup of loose tissue on the surface of the water to allow the microbes to focus more on the remaining meat on the bone.

- Check on the bones every week until they are free of meat.

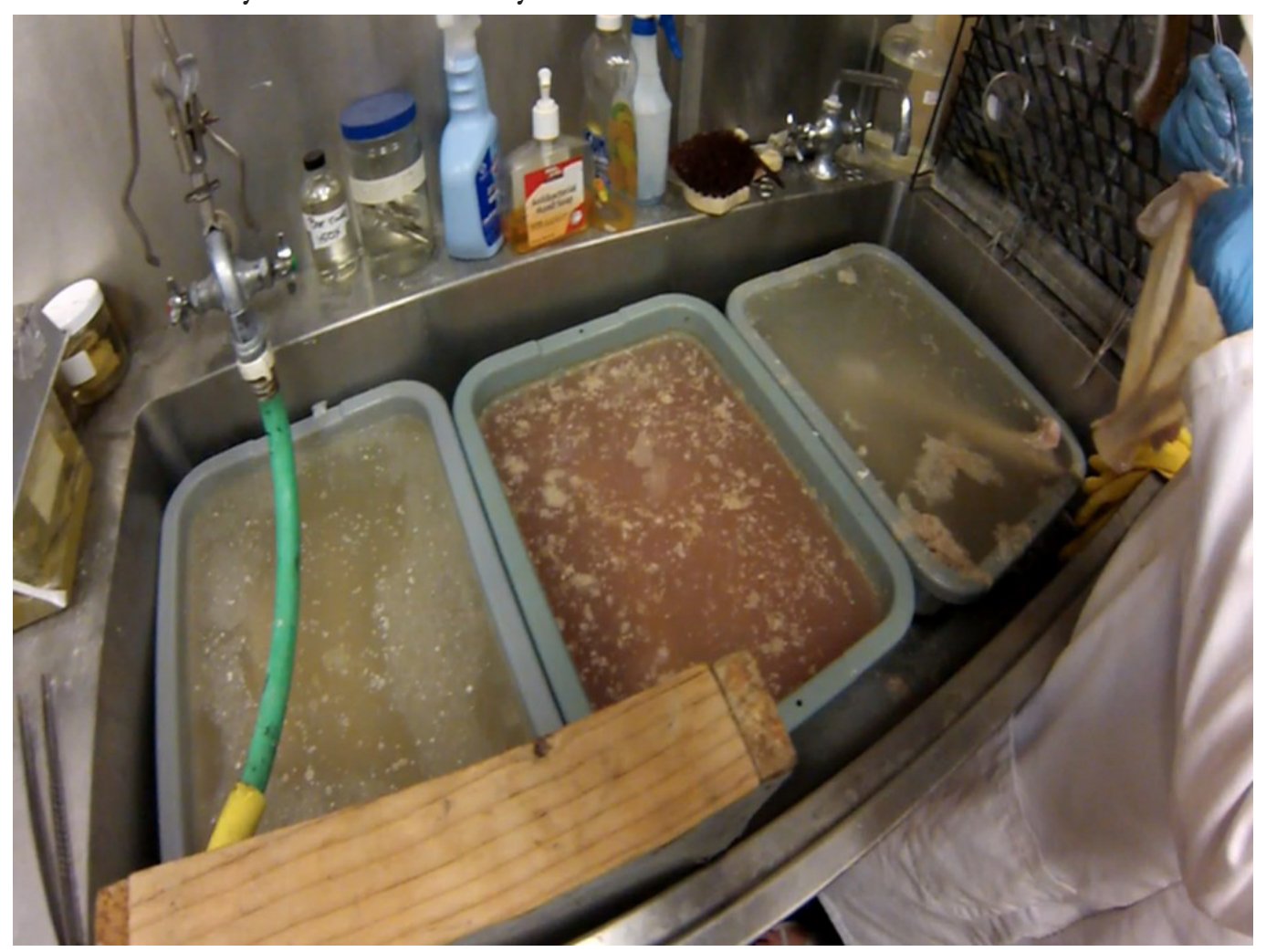

Figure 2 - Cold water maceration set-up. Bones are placed in sections inside tubs and left to sit for several weeks.

\section{Dermestid Beetles}

Dermestid beetles can refer to several different species of carrion insects within the family Dermestidae. The beetles are extremely proficient at cleaning skeletons. Colonies are able to take care of themselves without much maintenance; however, they do require close watching to keep conditions optimal. Depending on the size of the colony and container in which they live, a colony can clean a skeleton 
in days to weeks. The difficulty in maintaining a dermestid colony is ensuring they have enough food and keeping the environment to their liking. They operate best in environments from 70 to $80^{\circ} \mathrm{F}$ with the driest conditions as possible.

The number-one threat to a dermestid colony is mold growth, so make sure that the relative humidity is as low as possible - ideally below $40 \%$, at least inside their aquarium - to prevent the spread of fungal growth. This also means that you should feed them meat that has been dried out. Drying meat is simple. We have found that leaving meat in a room with a fan blowing over it will dry the meat in one to two days. Freezing the meat prior to drying will help the process as well. Dermestids represent a highly efficient form of cleaning as long as the colony is taken care of.

\section{Materials}

- 20-gallon aquarium (variable depending on size of specimen being cleaned)

- Rolled sheet cotton

- Paper towels

- 1/4" hardware cloth or metal grate

- Cardboard box containers

- Dermestid beetles

\section{Methods}

- Place a layer of rolled sheet cotton across the base of the aquarium, or just enough to cover the base. Our layer was about one inch thick.

- Place a metal grate or 1/4" hardware cloth on top of the cotton.

o This allows the substrate to build up under the dermestids without the bones falling through as they are cleaned. When enough substrate builds up, the metal grate can be pulled upwards on top of the substrate.

- Thread the vertebrae together with copper wire to keep them in order in case they disarticulate unexpectedly. Thread the ribs together in order as well, but not so tightly that it prevents beetles from going underneath the wire and consuming the meat.

- Place individual bones or sections of skeletons in individual cardboard box containers so the bones do not get mixed up, and so they remain in one place once the meat has been removed by the dermestids.

- Cover the boxes or containers with paper towels_-dermestids prefer to work in the dark.

- Allow beetles to colonize aquarium.

- Check on the colony daily or every other day to ensure no mold is growing in the container.

- The dermestid feces will serve as substrate and do not need to be removed. Once enough fecal material has built up, the metal grate can be shuffled to the top of the substrate, allowing the feces to fall below the grate on top of the cotton. 


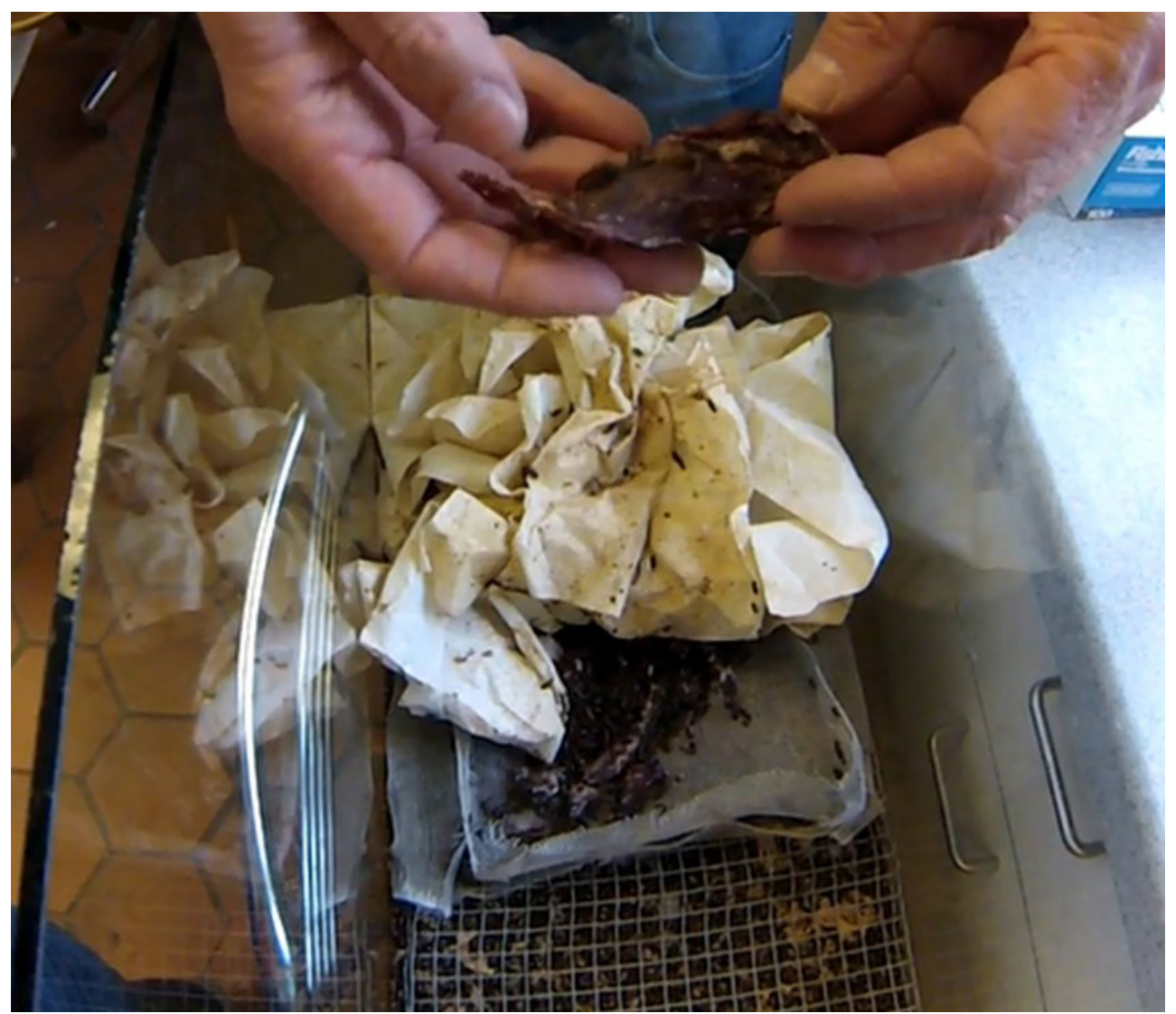

Figure 3-Dermestid beetle tank.

\section{Boiling and Maceration Combination}

This combination allows for the microbes in the tap water to digest the tissues more quickly by briefly boiling the bones first.

\section{Methods}

- See boiling and maceration protocols above for materials.

- Boil the skeleton until the meat has become dark in color (see photo below). o Remember to consider not boiling the skull as it may cause the teeth to crack. Cold water macerate the skull instead.

- Apply methods for cold water maceration treatment. 


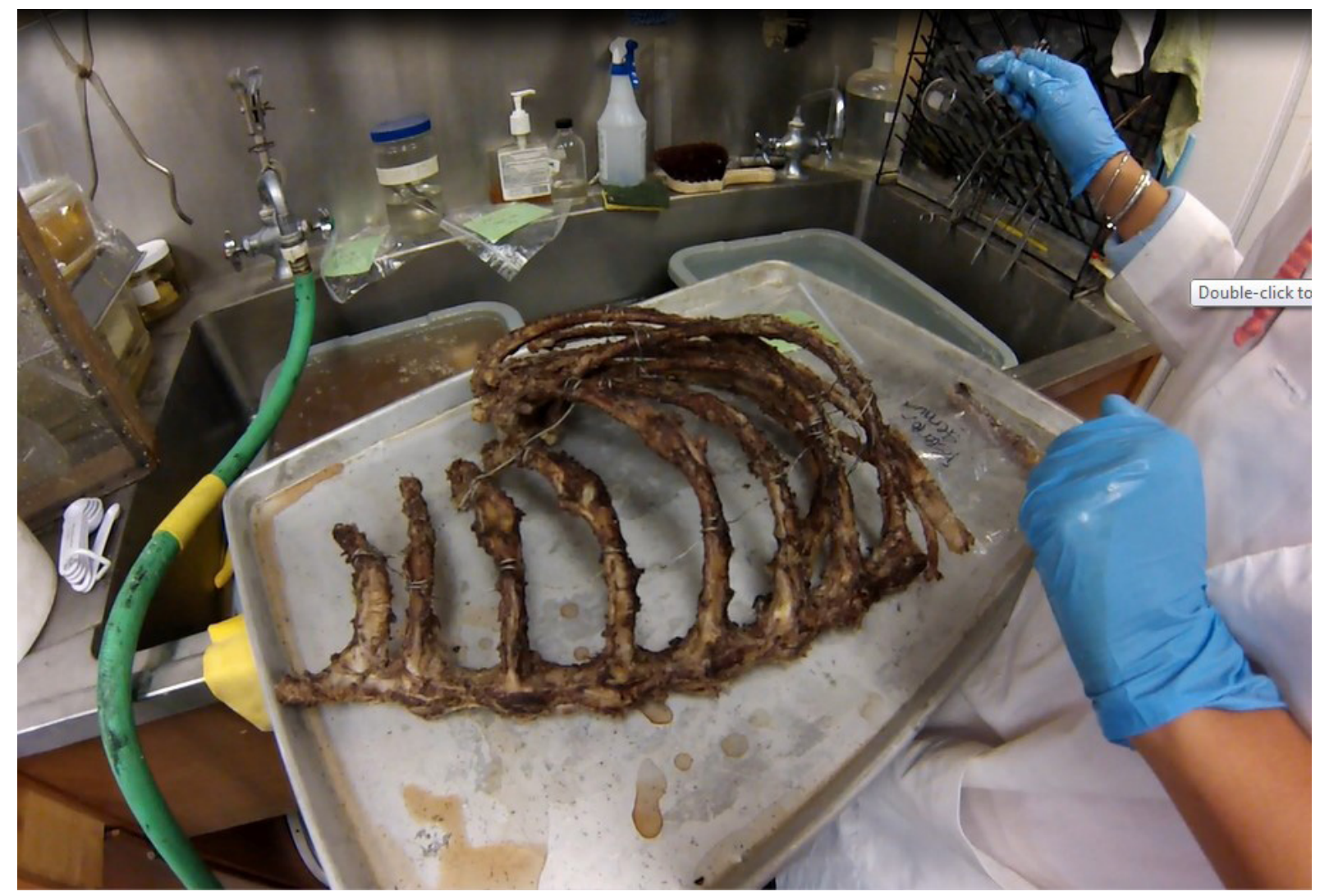

Figure 4-Boiled ribcage being prepared for maceration. This is an example of the proper color of meat after briefly boiling.

\section{Section II: Degreasing and Whitening}

\section{Degreasing the Skeleton}

Bone is porous, and bone marrow is greasy. If not degreased, the bones will remain a yellow color and continue to leach a layer of oil over the entire specimen, making it difficult to work with and harming the structure of the bones over time. In order to prevent this, the oil must be drawn out from the bone marrow cavity. There are several ways to accomplish this, but this protocol will focus on what we became familiar with: white gas.

White gas, or Coleman fuel, is highly volatile and releases harmful fumes. Work with extreme caution when handling white gas. Work in a highly ventilated area, preferably with a fume hood, and do not expose the fuel to excessive amounts of heat in order to avoid combustion. The gas will also warp most types of plastic, which can cause loss of seal and loss of fuel due to evaporation. To avoid excessive warping, make sure the container in which you are storing the fuel is thick and strong. We used a Leaktite 5-gallon bucket from Home Depot with a screw-top lid; larger buckets can be found to cover larger bones. Metal and glass containers will not warp. Keep a close eye on this process, as white gas is not healthy for the bones and, if overdone, can leave a chalky residue.

\section{Materials:}

- Coleman fuel 
- Plastic, glass, or metal container with sealable lid

- Well-ventilated workspace

- Gloves

\section{Methods:}

- Drill a small pilot hole in both ends of the bone. This will help draw out the grease.

- Fill the container with enough Coleman fuel to entirely cover the bone.

- Seal the lid.

- Check on the bone after 4 days. If a visible layer of grease or oil has collected on the surface of the gas, decant the grease and dispose of it as hazardous waste. The grease will not always be visible, though. If it is not, leave as is and reseal the lid.

- Leave the bones in the white gas for 7 to 9 days total.

- Remove bones from white gas and allow to air dry for I day.

o The white gas (Coleman fuel) can be used again! Decant any visible grease or oils and reuse what you have.

o Treat Coleman fuel as hazardous waste; if you are going to dispose of it, do so at a proper treatment plant.

- The bones may still appear greasy even after white gas treatment. This is due to the last layer of grease remaining on the surface of the bone. This layer will be removed in the next section.

\section{Whitening the Skeleton}

As with all the other sections of this protocol, there are several options for whitening the bones. The chosen method generally correlates with the degree of whiteness that the artist or scientist is trying to achieve. For example, $30 \% \mathrm{H}_{2} \mathrm{O}_{4}$, or chemical grade hydrogen peroxide, will bleach the bone paperwhite, but is also quite harmful for the structural integrity of the bones and to human skin. Commercially purchased hydrogen peroxide, or $3 \%$, is also an option. A bath of $\mathrm{NH}_{4} \mathrm{OH}$, or Ammonium Hydroxide, is another option. Again, as is typical in this protocol, we will discuss what we used and why.

Bones are naturally off-white with a slightly yellow or ivory tinge. Paper-white is often seen in factoryprepared skeletons, and the degree of bleaching is mostly a matter of preference. In order to stick as closely to nature as possible, we used a method of whitening involving Biz laundry detergent, which is the least invasive to the bone and mostly serves to even out the color tone and remove remaining grease or stains.

\section{Materials}

- Biz laundry detergent

- Plastic containers

- Tap water

- Measuring cups

\section{Methods}

- Fill containers with water.

- For every gallon of water, add a cup of powdered Biz laundry detergent. 
- Mix the solution until the Biz has dissolved.

- Place bones in solution.

- Leave for 4 to 7 days.

- Remove from Biz solution.

- Rinse the bones thoroughly under running water.

- Fill new or cleaned containers with tap water.

- Soak in clean water for 2 days.

- Remove and let air dry for I day.

\section{Section III: Articulation}

\section{Materials}

- Cold-rolled steel

- Hot glue gun

- Devcon epoxy

- PCir epoxy

- Drill

- Vice

- Bull cutters

- Rod bender

- Metal shears

- Tape measurer

- Pencil and pen

- Labeling tape

- Life-sized specimen printout

- Spatula 


\section{Methods}

Spine

- Drill through the marrow cavity of the cervical, thoracic, and lumbar vertebrae.

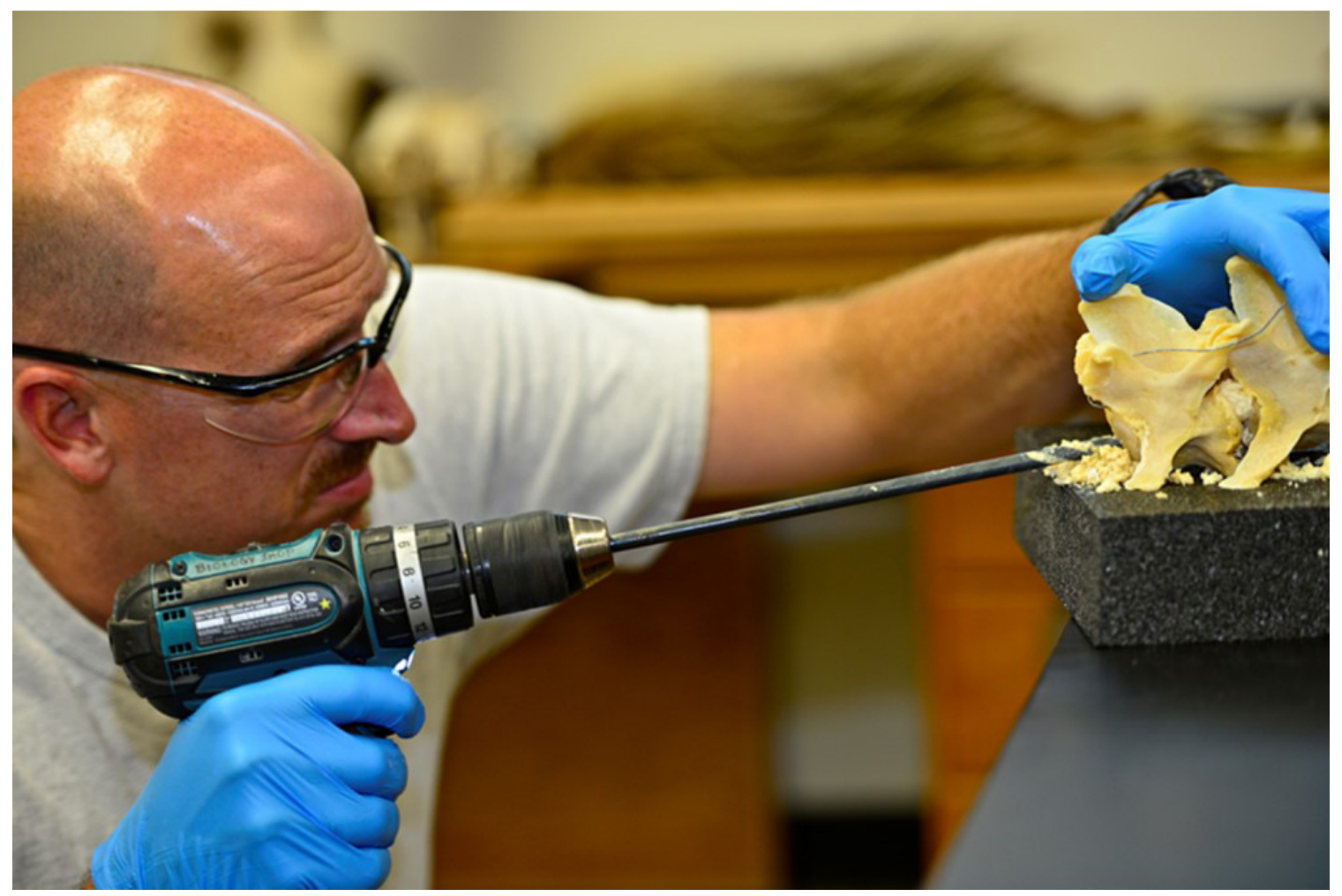

Figure 5 - Drilling through the marrow cavity of the spine.

- Measure the appropriate length of steel for each section of vertebrae - thoracic, lumbar, and caudaland feed the metal through the drilled cavity. You can run several pieces of steel through the vertebrae or run a single longer piece. We had one rod for each section of the spine, and the rod would feed about two or three inches into the next section of vertebrae until it touched the next rod.

o Note that the thickness of your rod will depend entirely on the size of the organism and the drill bits being used. Decide which drill bits will be appropriate for which bones, and use a rod that is at least $\mathrm{I} / 8$ " thinner than the drill bit so that there is room for the hot glue and to allow maneuvering of the rod as you work.

- Trace the spine onto your printout of the specimen in order to represent an accurate curvature of the spine. 


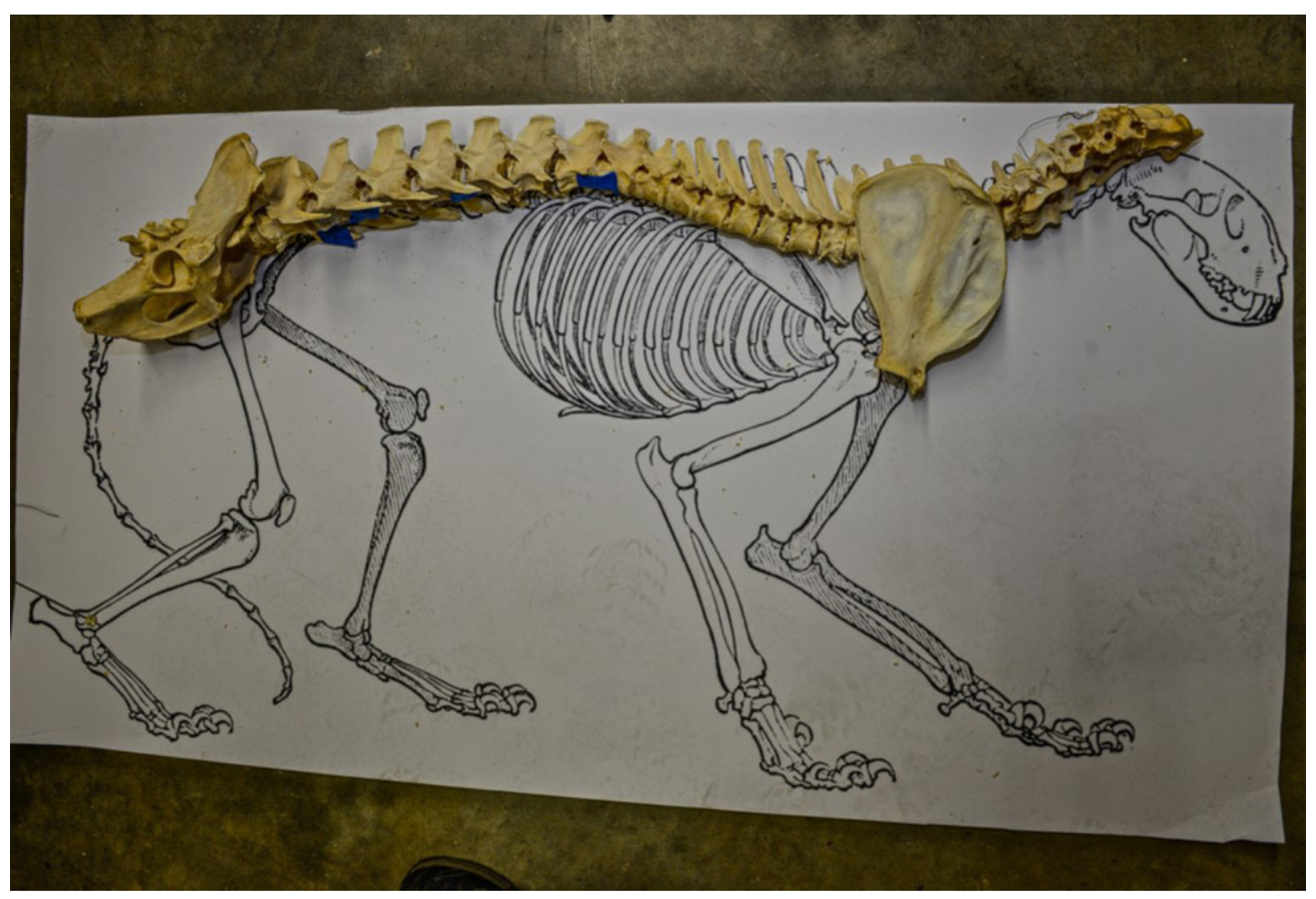

Figure 6-Tracing the spine on the printout.

- Articulate the spine. Pour hot glue onto the steel rod and feed it through the spinal cavity. Once the rod is locked in place, connect the other sections of vertebrae with the rod and hot glue. Work quickly, as hot glue dries quickly
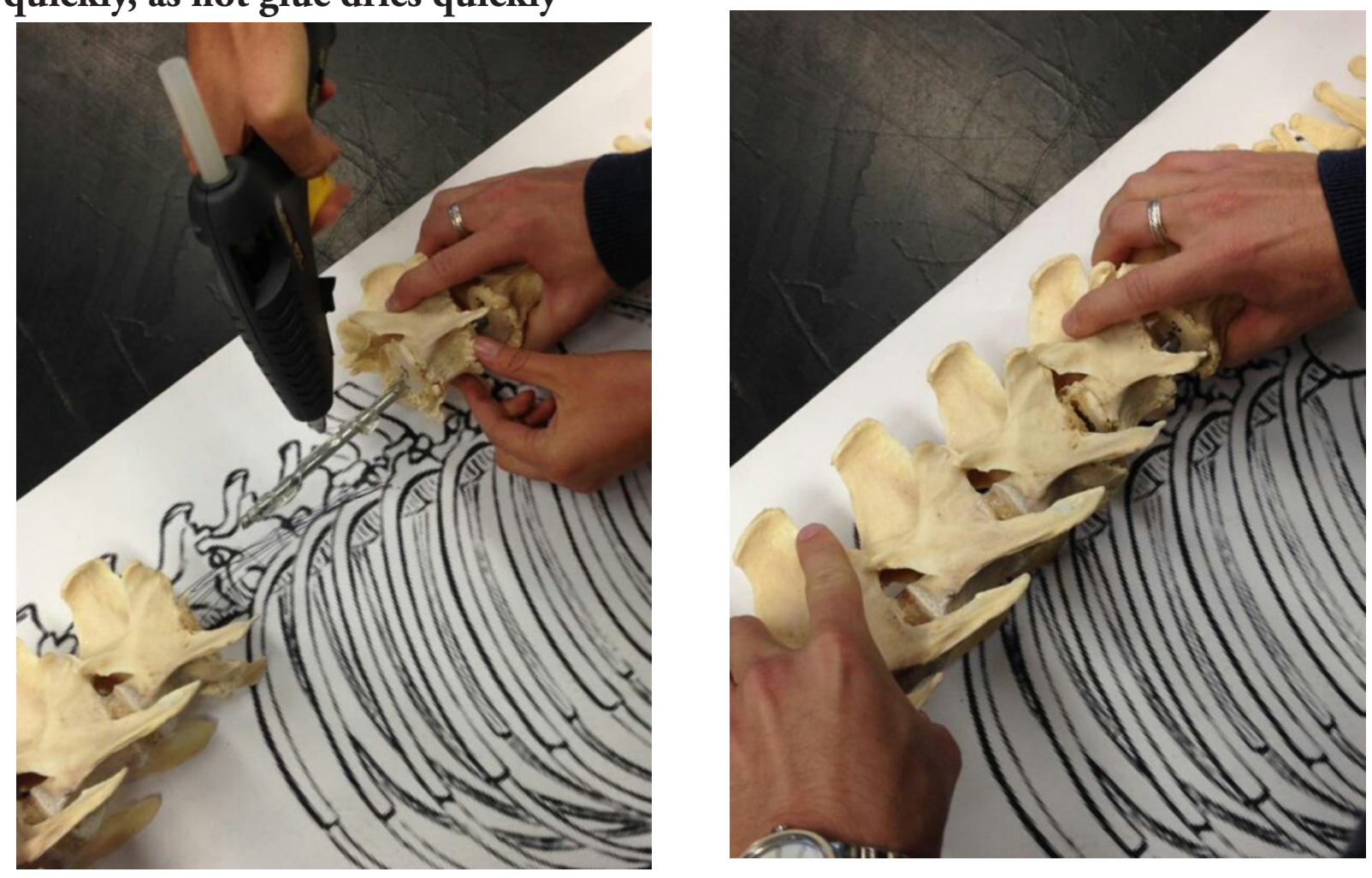

Figure 7-Applying hot glue to the rod before articulating cervical and thoracic vertebrae. 
- At this point, it is difficult to proceed without construction of the base on which the skeleton will be mounted. Decide where the major supports should be placed and build a base consisting of a wood panel and at least two support rods on which the vertebrae will rest. Place the articulated vertebrae back onto the printout and measure from the points of support on the skeleton to the ground.

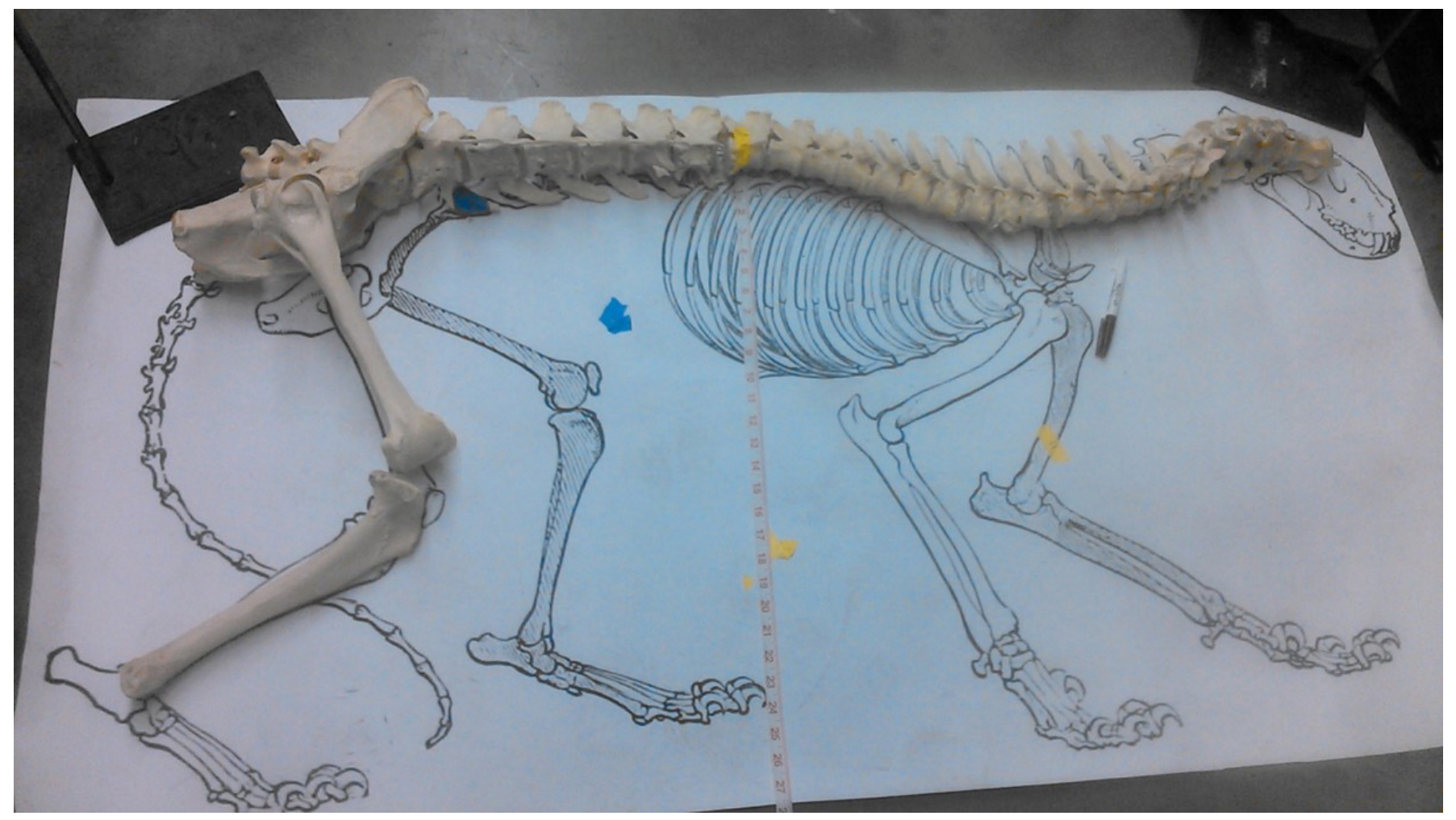

Figure 8-Measuring the distance between the base and where the support will go.

- Once measurements are taken to determine distance from the ground to the specimen, build the base. You should be incorporate a bar that runs perpendicular to the front support rod to which the front legs will be articulated.

- Mount the vertebrae on the base. We used copper wire to tie the spine to the support rods.

- Hot glue the ribs into place. 


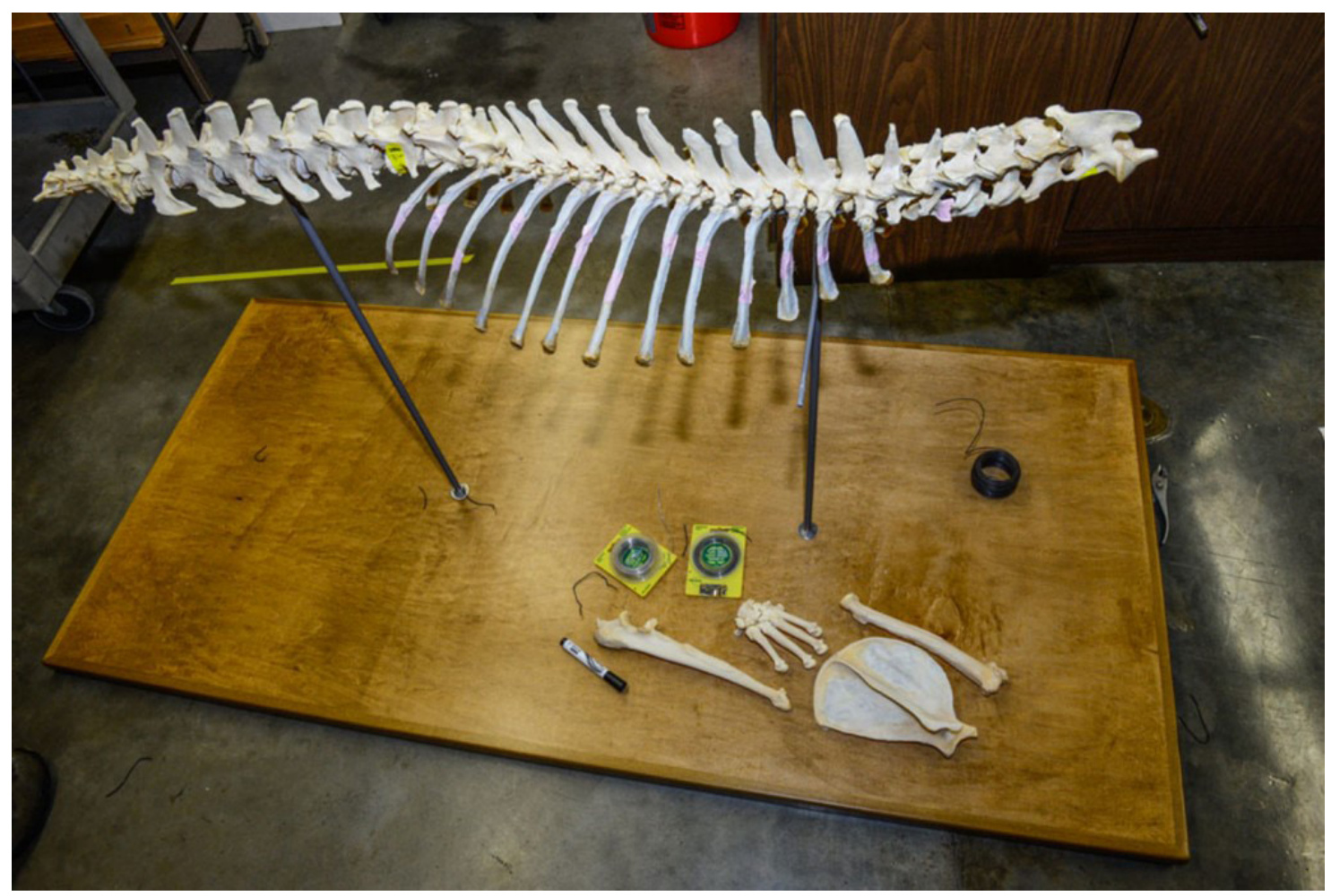

Figure 9-Articulating the ribs and mounting the spinal column to the base.

\section{Front legs}

- Trace the desired angle of the front legs on the printout.

- With pencil, draw a line across the bones to mark where you will line up your drill bit.

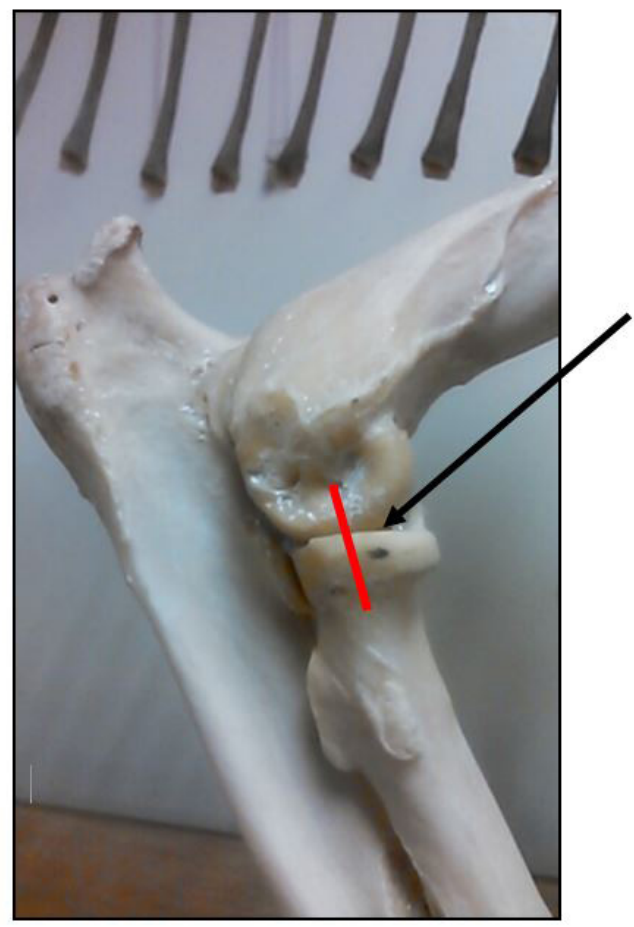

When holding the bones in place before drilling, draw a line here with pencil from one bone to the next. When the bones are taken apart to be drilled, the line will tell you how to line up your drill bit.

Figure Io - Shown above is an example of where to make a pencil mark to ensure proper drill alignment and placement. 
- Drill into the articulation joints of the bones until you reach the marrow cavity.

- Measure the length of rod required to articulate the bones.

- Fill the cavity with hot glue and articulate the radius, ulna, and humerus.

o Note that the images below show the rear (or hind) leg bones as these were the only limbs we had photo documentation for, but the same methods apply for the forelimbs.

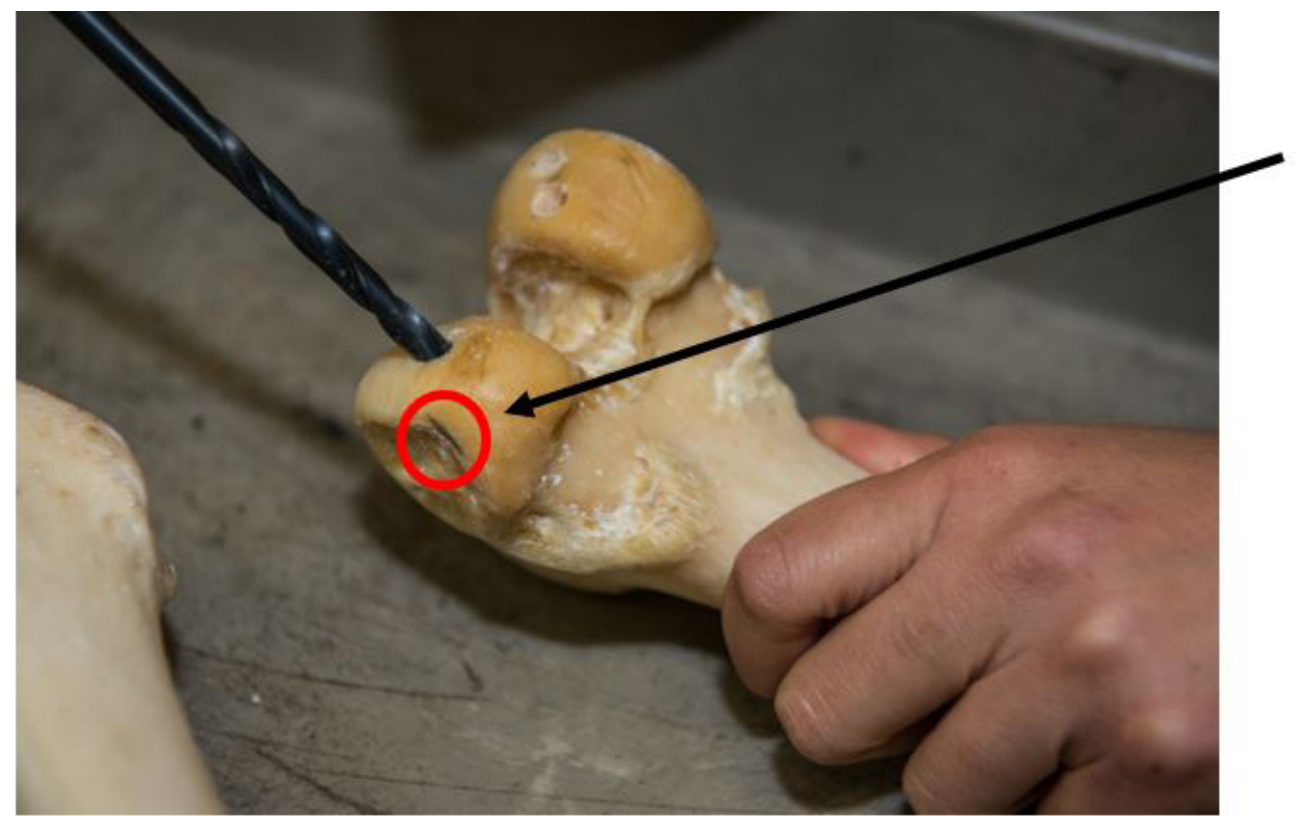

Use the pencil mark to line up the drill bit.

Figure II - Drill alignment along the axis of the pencil mark on the side of the bone.

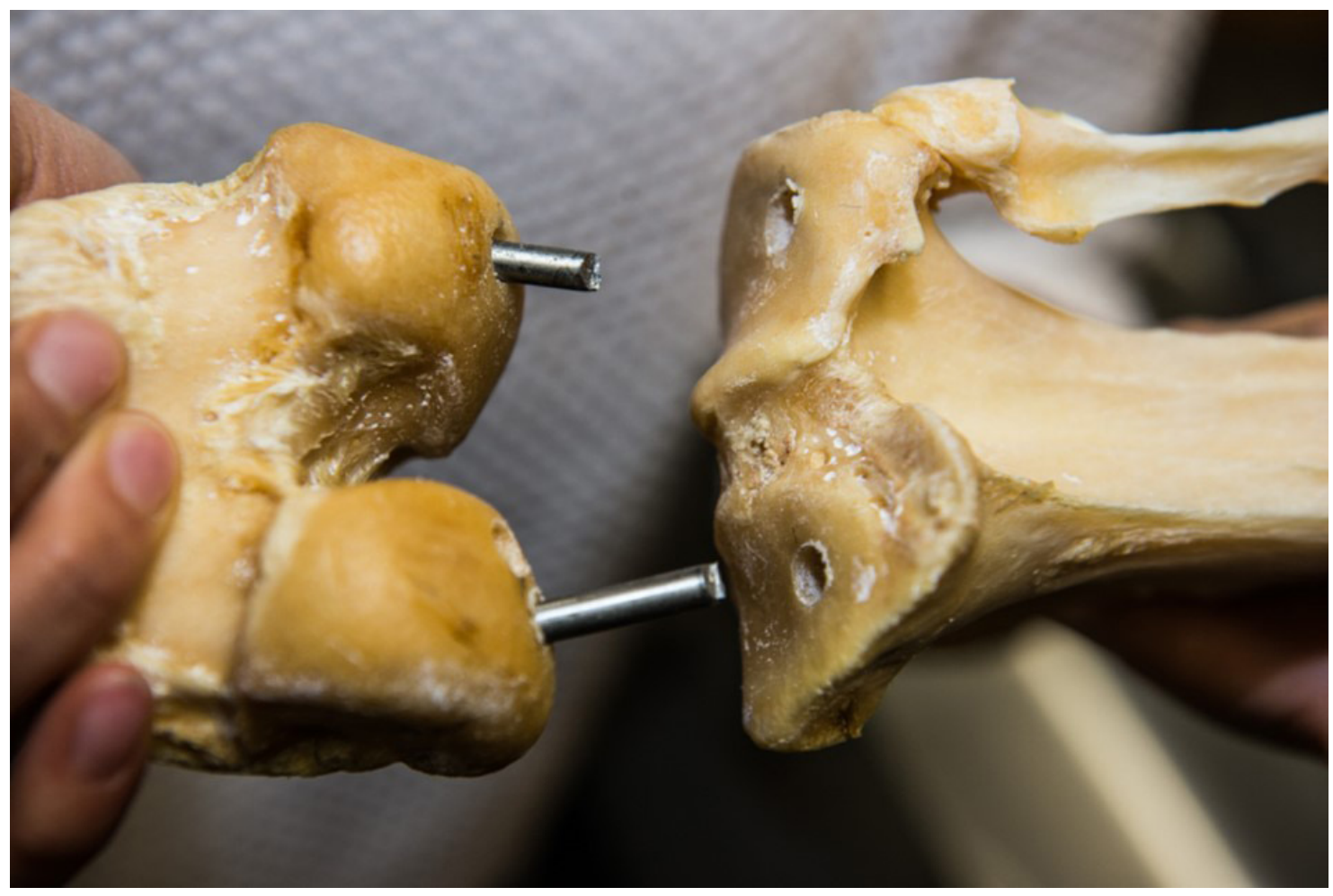

Figure I2 - Line up the rods and drill holes in preparation for articulation. 


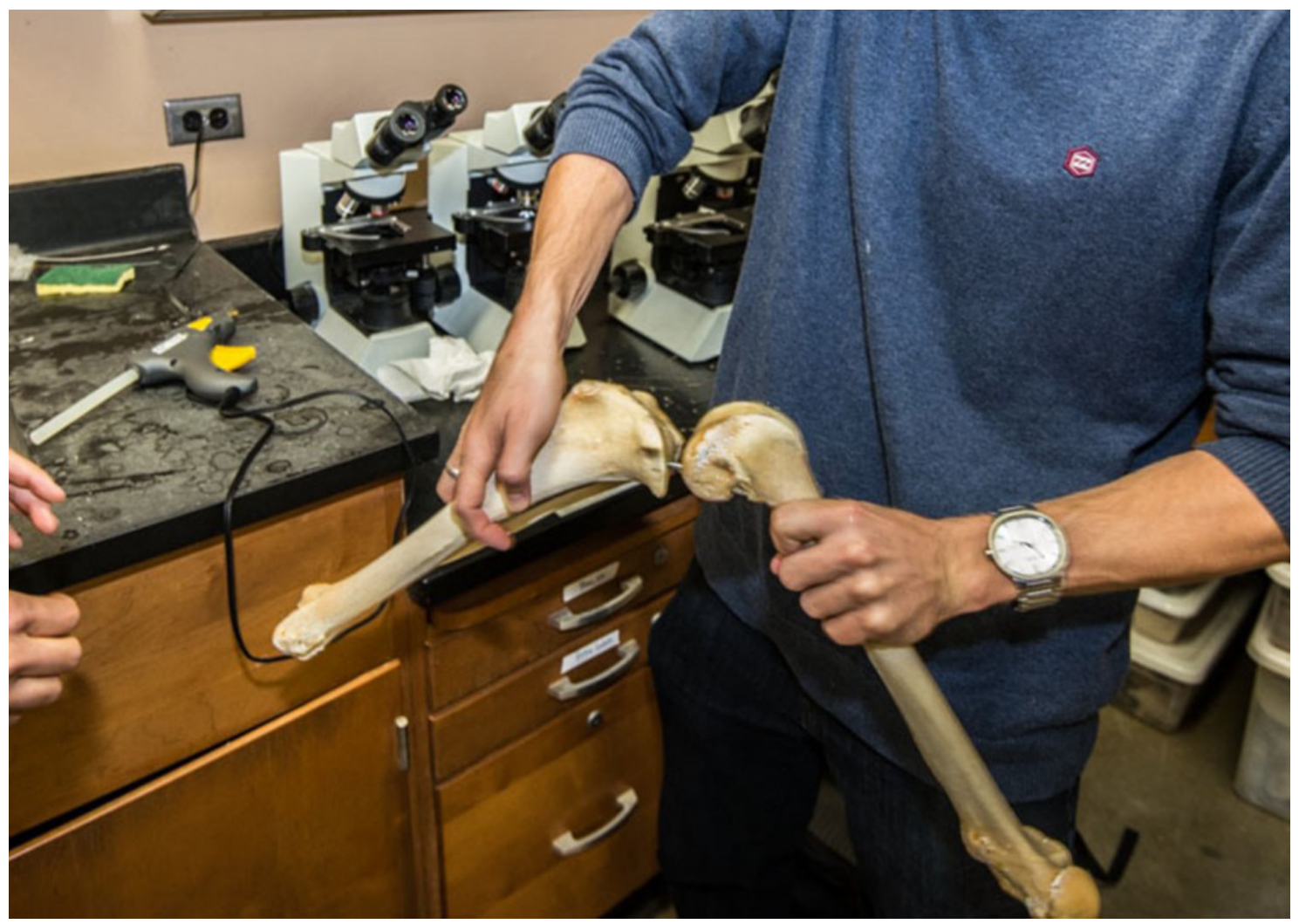

Figure 13 - Hot glue applied to the rod and bones articulated at the desired angle.

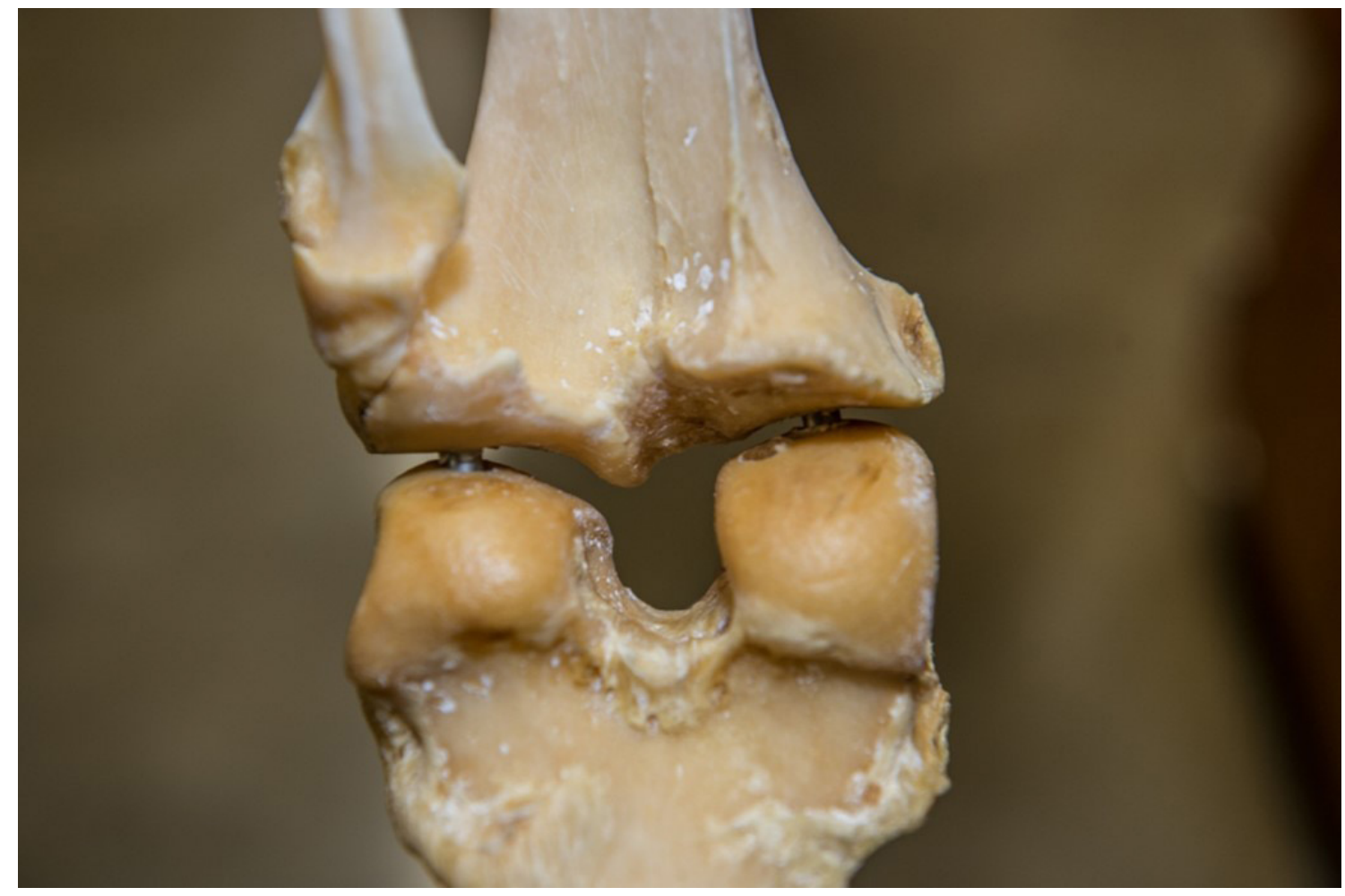

Figure I4 - Close up of articulated bones. 


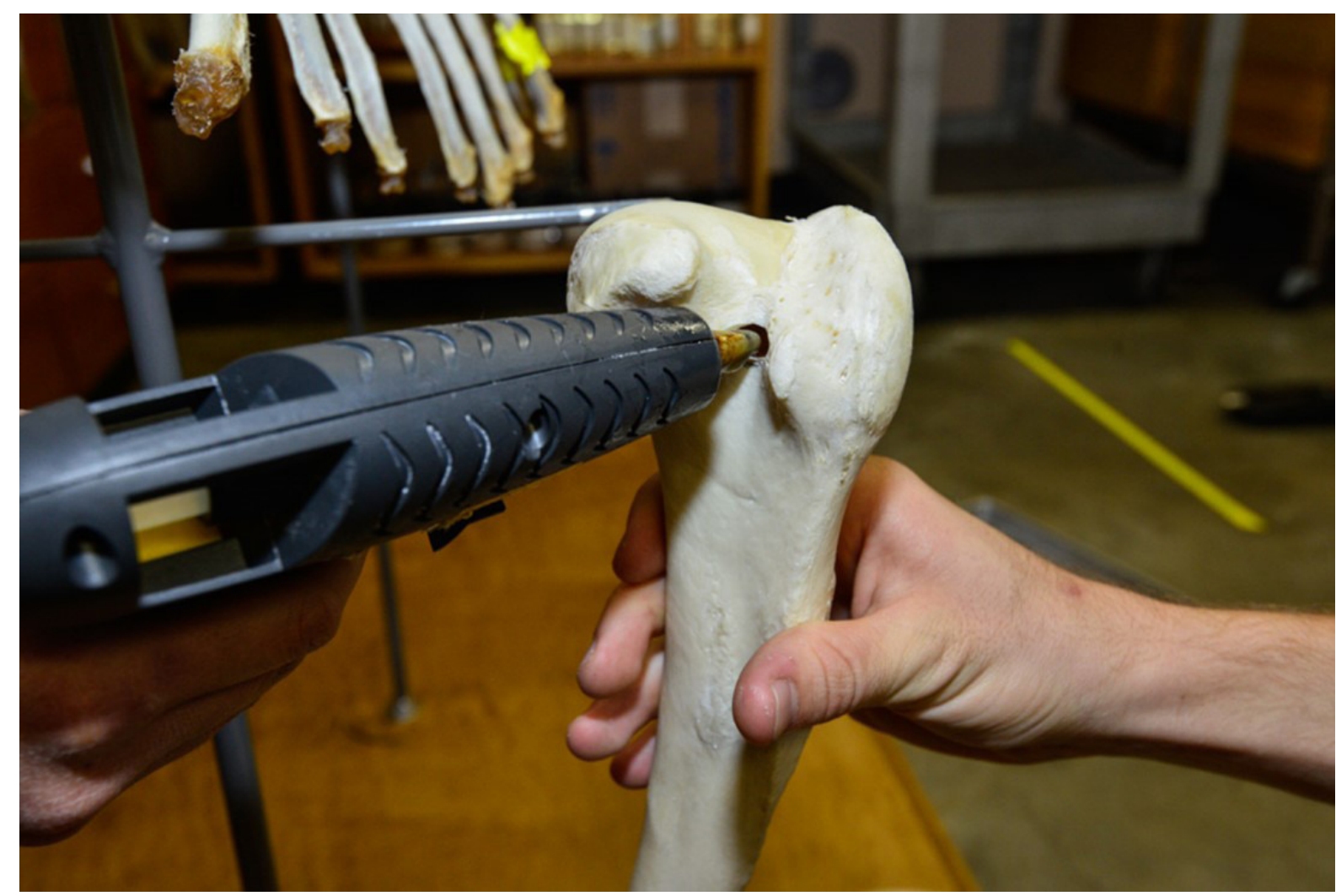

Figure IS - Filling the drill cavity with hot glue in preparation for mounting to the cross bar on the base.

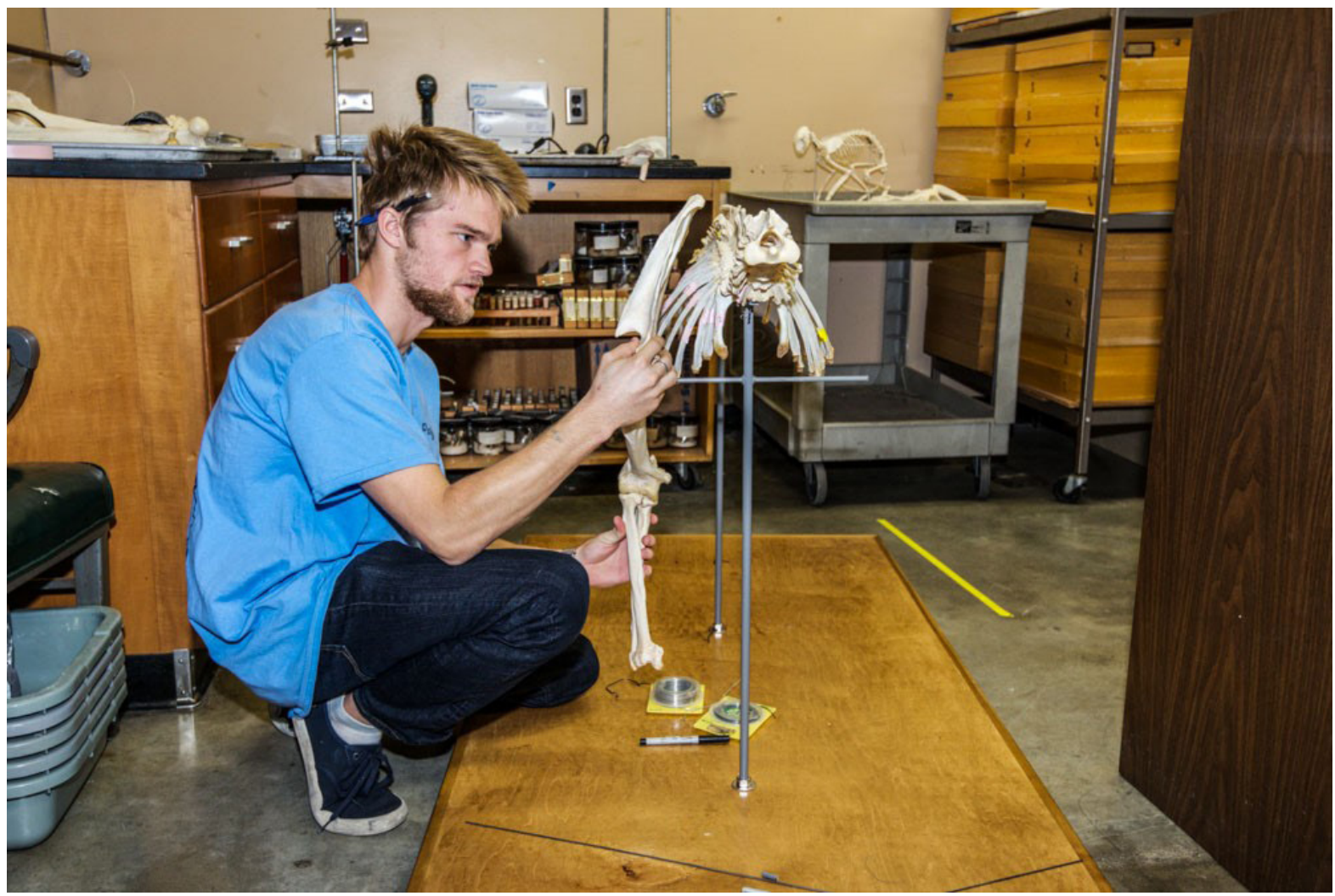

Figure I6-Mounting the front leg and lining up the scapula in preparation for tracing its placement. 


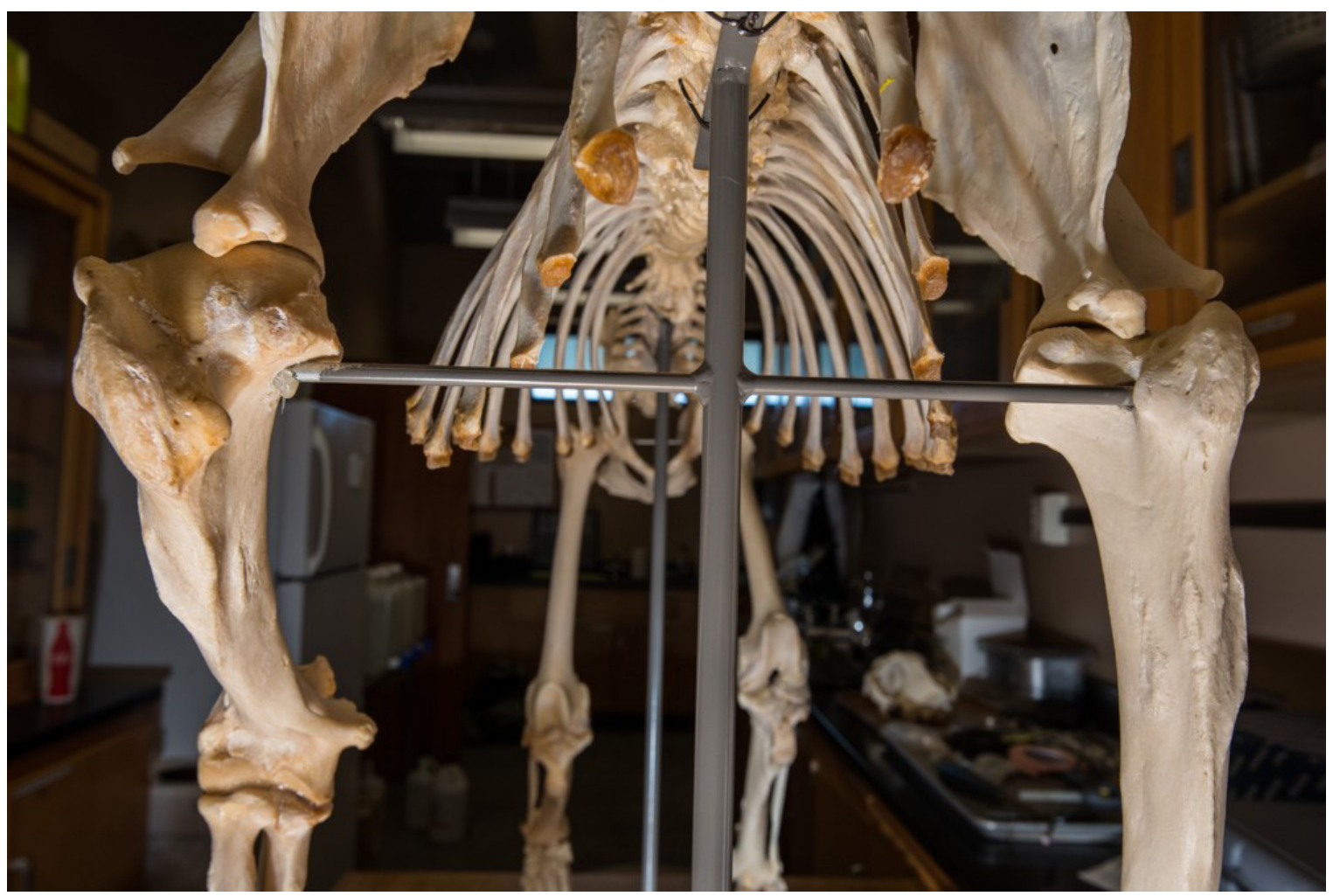

Figure I7-Above is a close-up image of the cross bar on which the front legs are mounted.

\section{Front and Back Paws}

- Refer to the Atlas of Animal Anatomy for Artists in preparation for articulating the front and back paws. Pay careful attention to the orientation and location of each individual bone. Hot glue the forefeet and hind feet together one bone at a time, starting with the wrist and working down to the carpals. Leave the metacarpals and phalanges disarticulated until the foot is mounted to correct the gap between the base and the carpals.

- The front feet can be drilled and mounted with metal rod to the radius. The metacarpals and phalanges can be glued on one at a time at the appropriate angle, accounting for the distance between the carpals and the base.

- No wire is required for the feet-hot glue will be sufficient.

- Articulate the hind feet with hot glue. Refer to the Atlas of Animal Anatomy for Artists. Do not glue the metatarsals and phalanges on until you mount the hind feet in order to have full control over the angle and any unforeseen gaps.

\section{Pelvis and hind legs}

- Drill into the sacral vertebrae and the inside of the corresponding process on the pelvis.

- Mount the pelvis using hot glue and steel.

- Articulate the hind legs using a similar protocol as the front legs.

- Drill through the acetabular fossa and into the corresponding fovea capitis (see images below).

- Mount the legs onto the steel bar.

- Drill into the talus and the tibia and, using the steel rod and hot glue, mount the hind feet. 


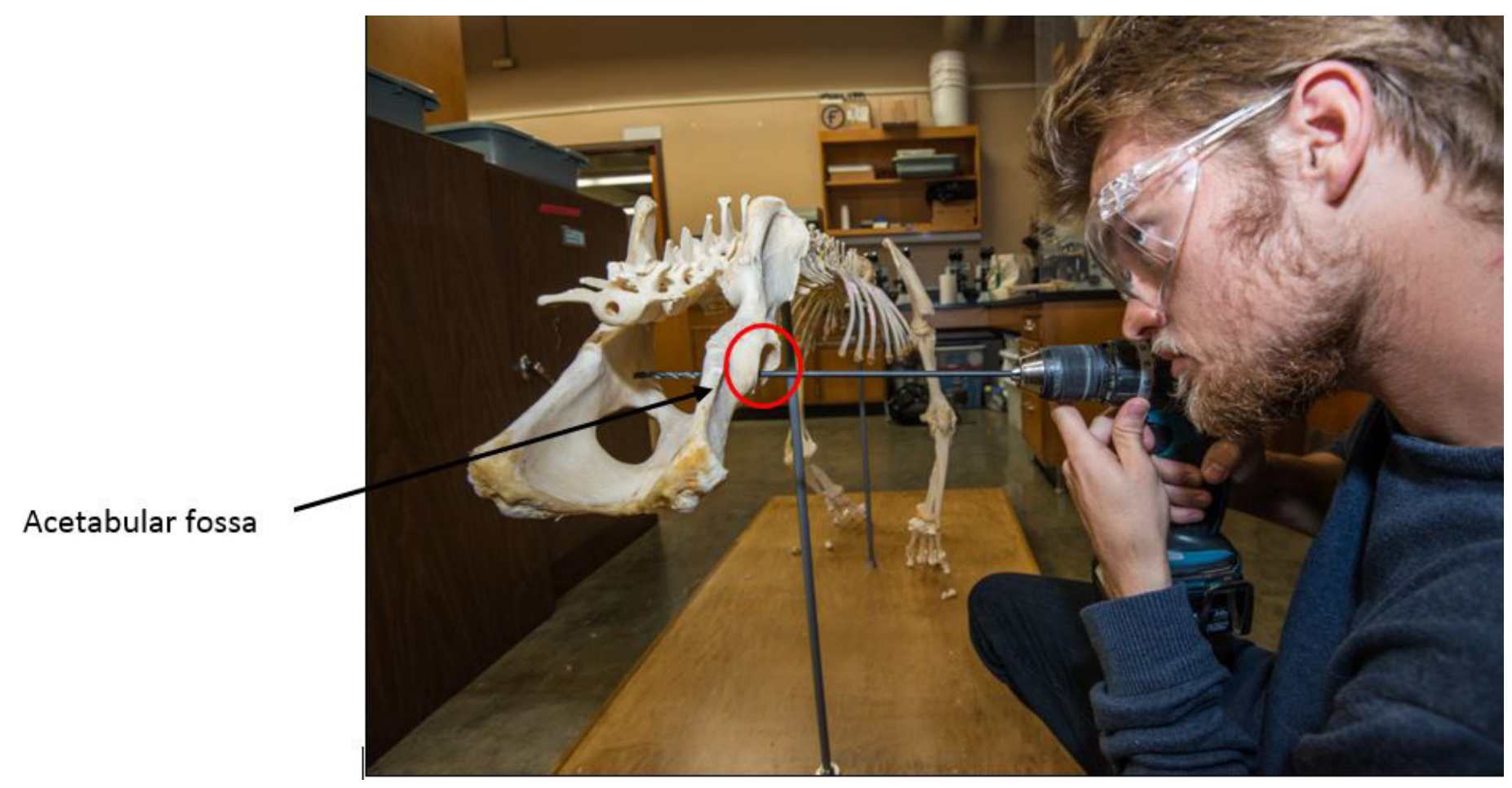

Figure I8 - Drilling through the acetabular fossa.

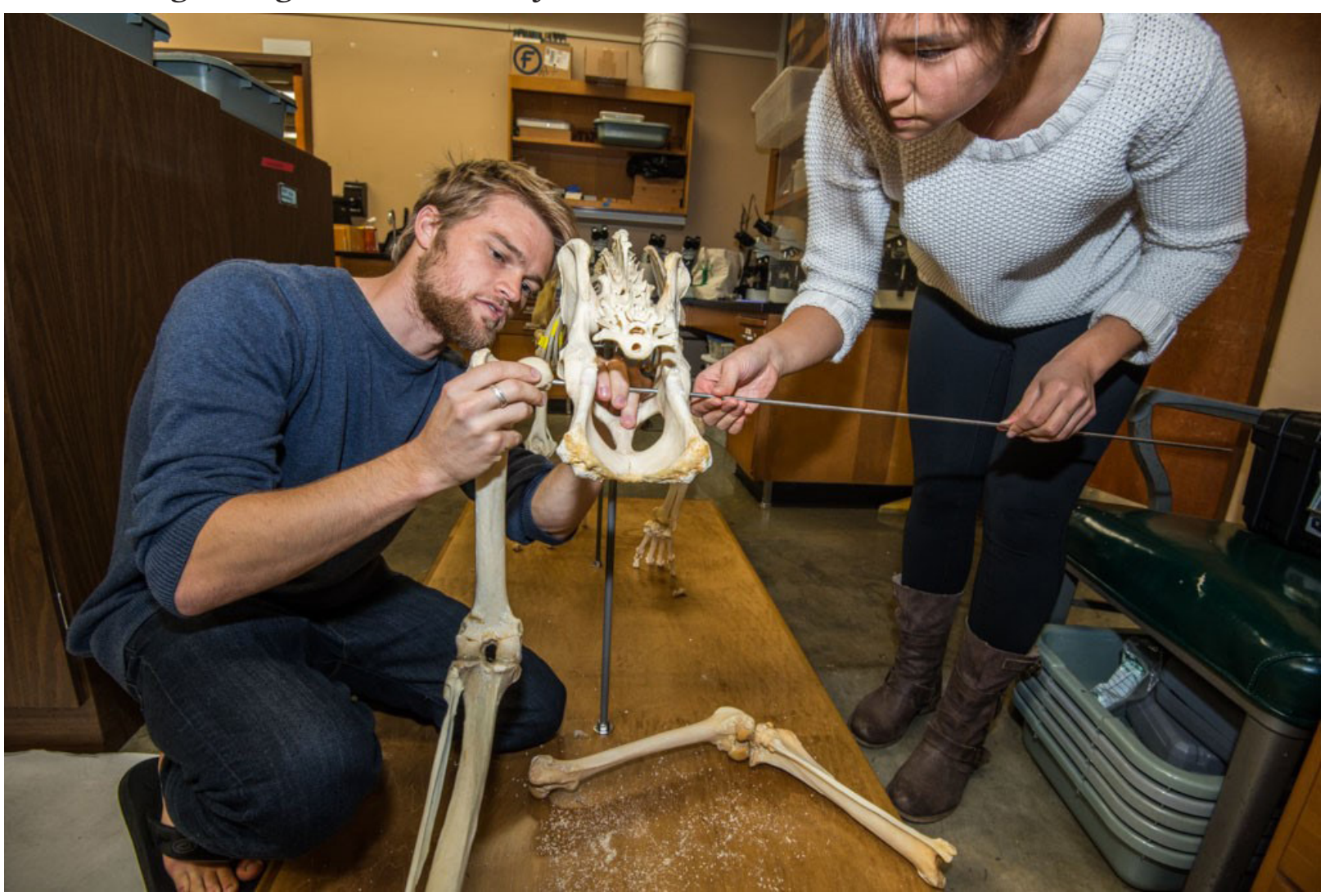

Figure Ig - Measuring the length of rod that will articulate both hind legs through the pelvis. 


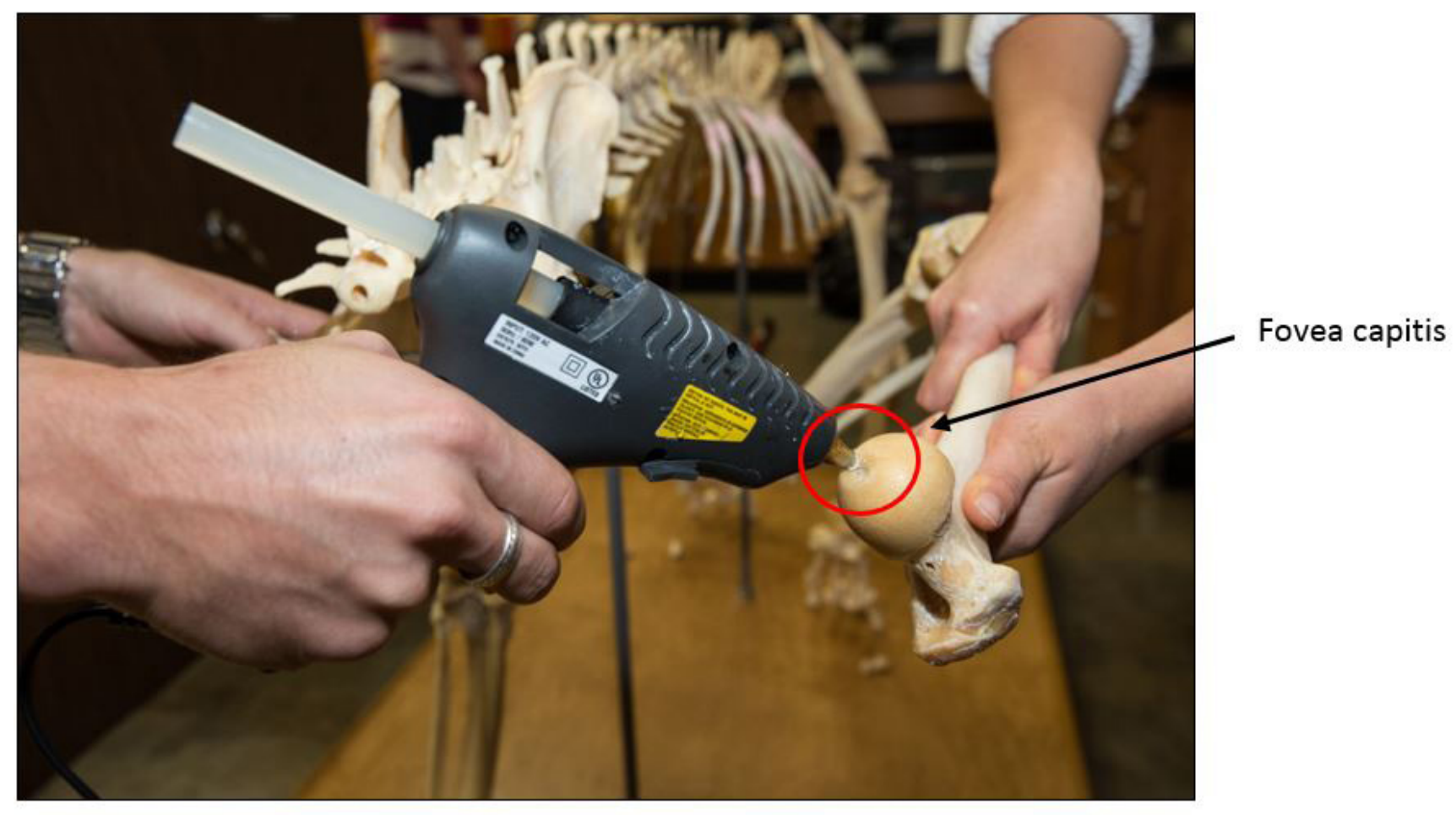

Figure 20 - Hot gluing the drill cavit in the fovea capitis in preparation for articulation.

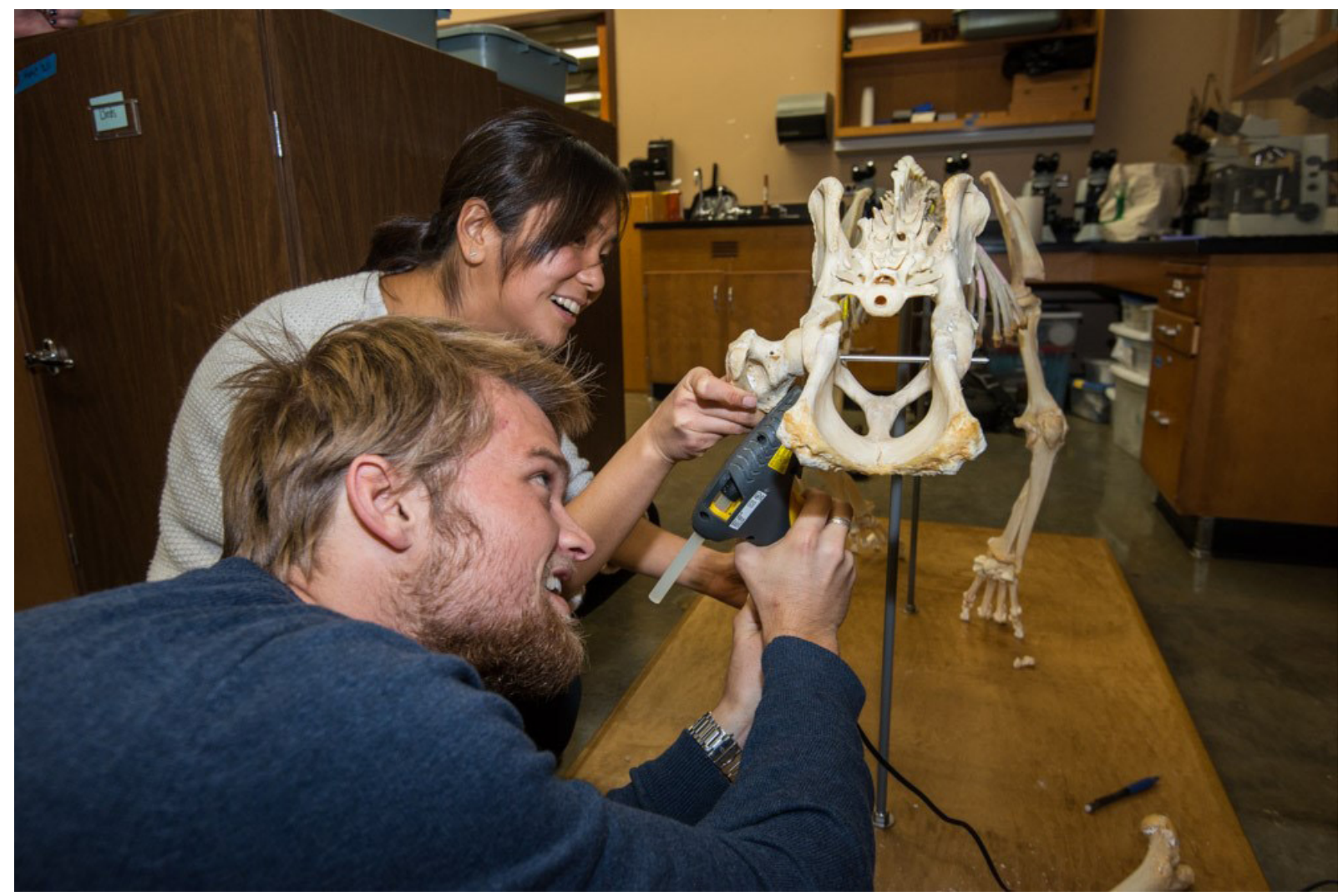

Figure 2I-Mounting the hind left leg. 


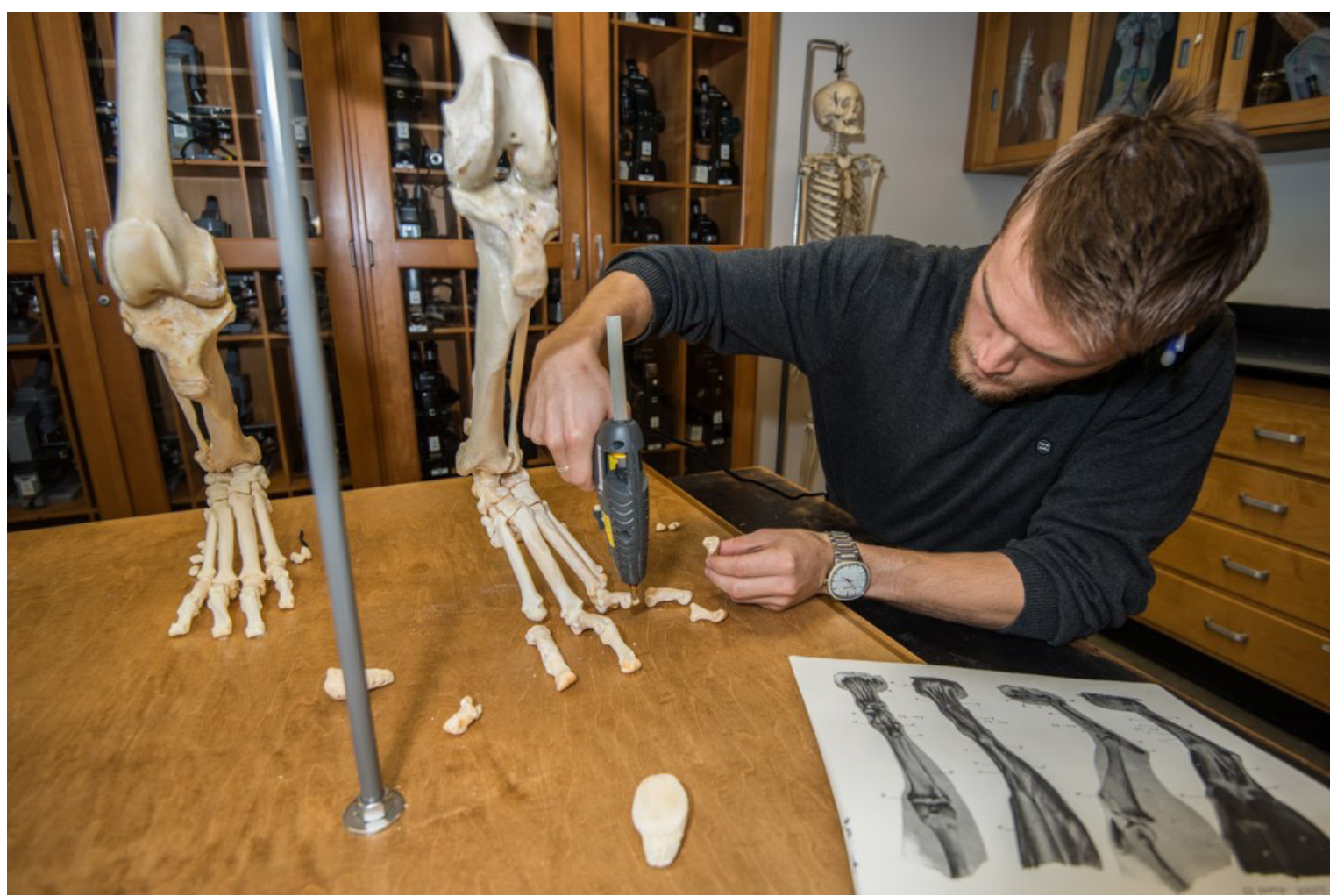

Figure 22 - Hot gluing the metatarsals and phalanges, using the Atlas of Animal Anatomy for Artists as a reference.

\section{Tail}

- Begin drilling through caudal vertebrae in preparation for mounting the tail.

- Choose the appropriate thickness of metal.

- As with the vertebrae, run the metal through the tail either through each individual section of vertebrae or through the entire piece.

- Mount the tail.

o The tail is rather fragile and tapers off in size toward the tip. For this reason, it will break easily if bumped. The tail can be outstretched if the base is long enough, but if there is not enough room, mount the tail under the legs or wrap it around the side of the skeleton as we did. 


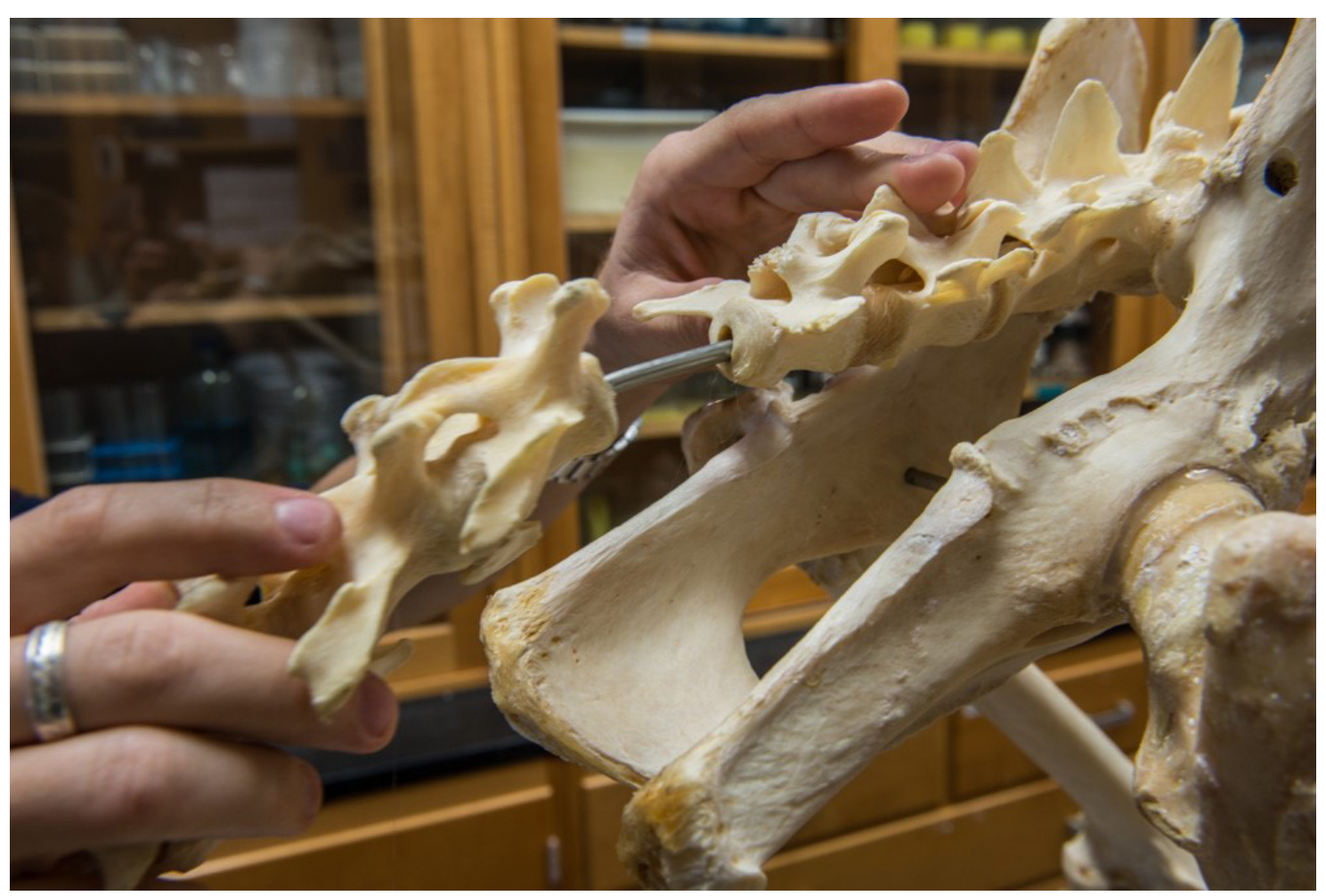

Figure 23-Articulating the caudal vertebrae with rod and hot glue.

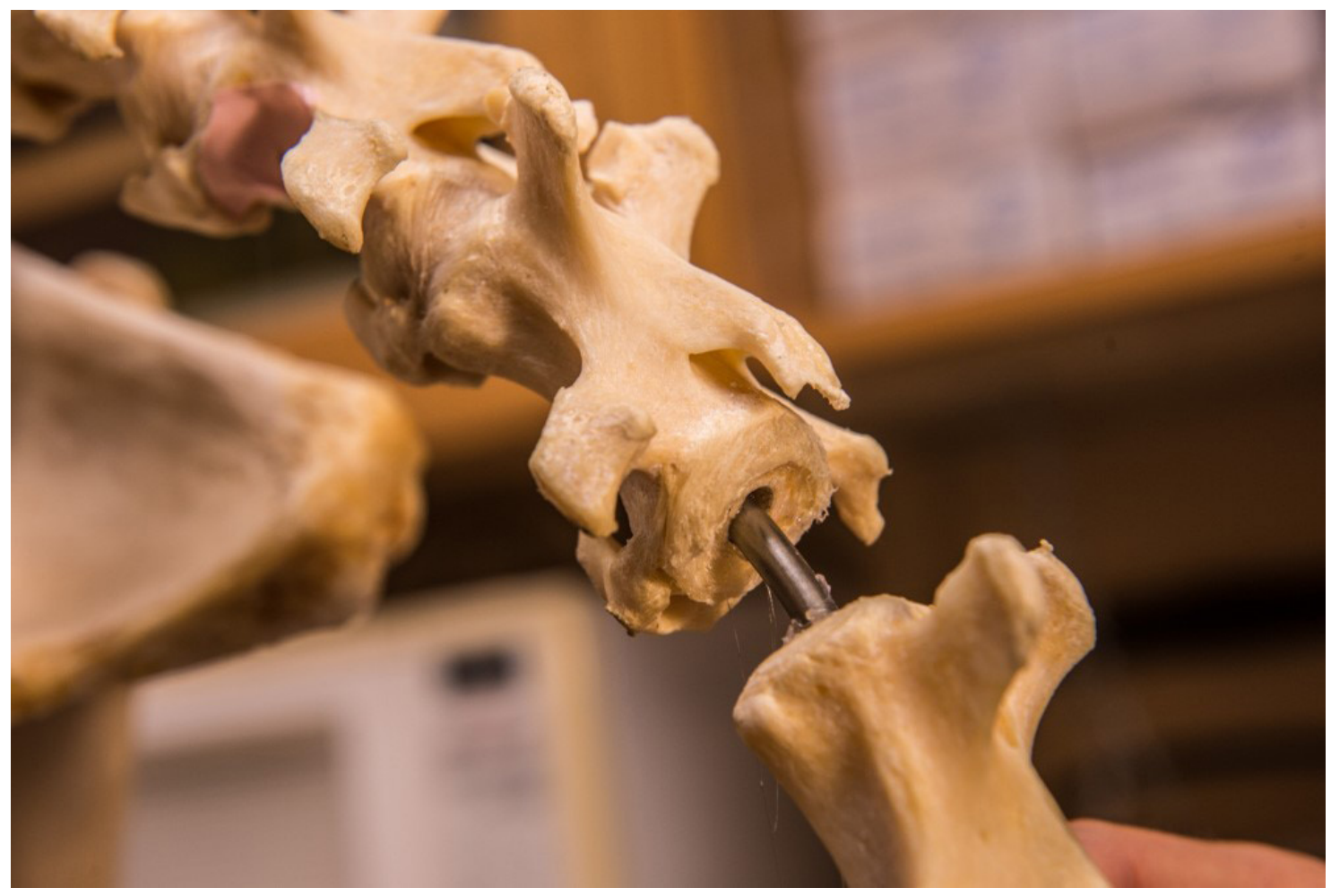

Figure 24-Close up image of articulating caudal vertebrae. 


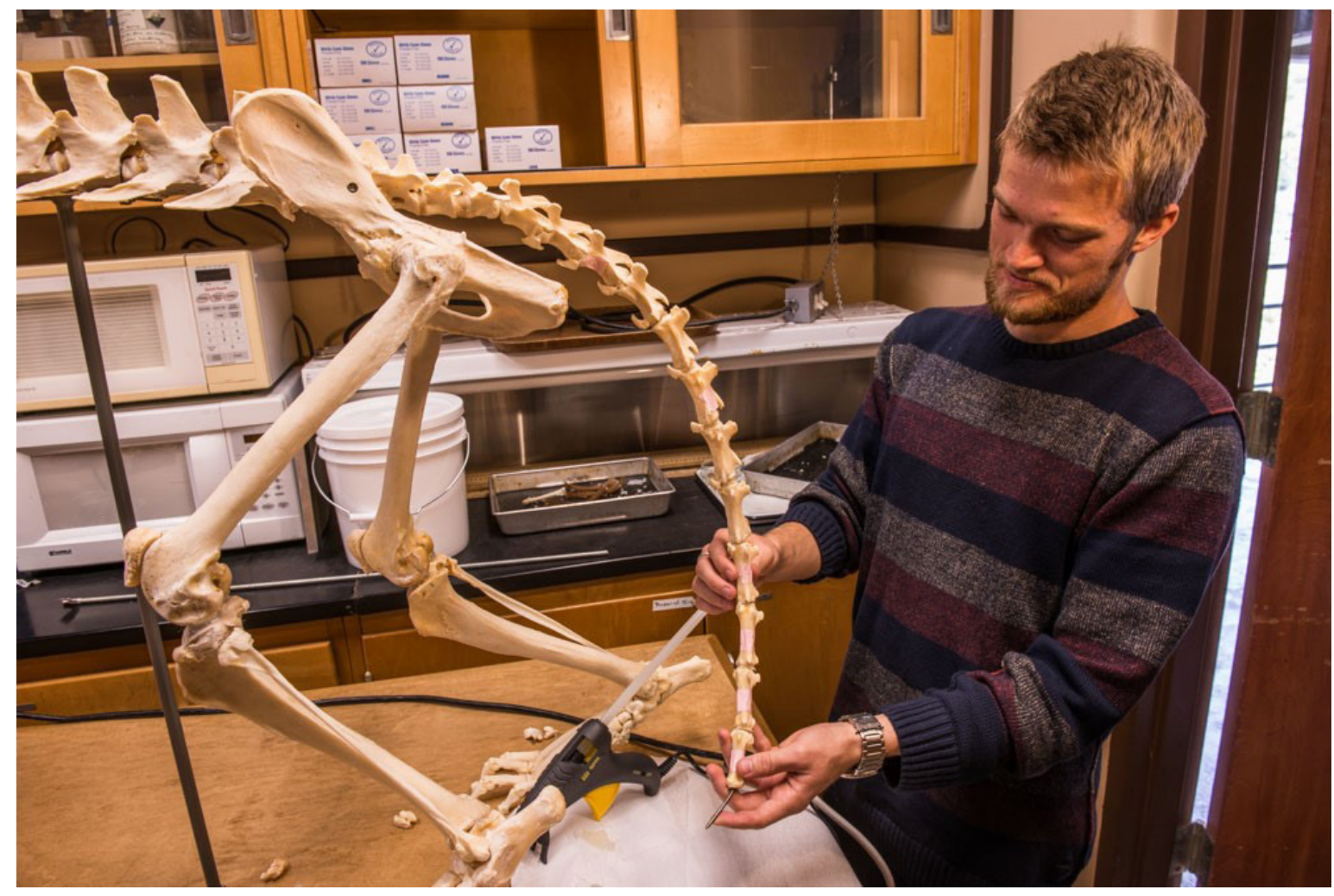

Figure 25-Image showing the direction we turned the tail in order to prevent it from hanging off the base.

\section{Skull}

- Measure the necessary length of rod needed to mount the skull.

- Secure a rod that runs out of the cervical vertebrae that will enter the foramen magnum.

- Bend the rod at the desired angle based on the direction you wish the skull to face.

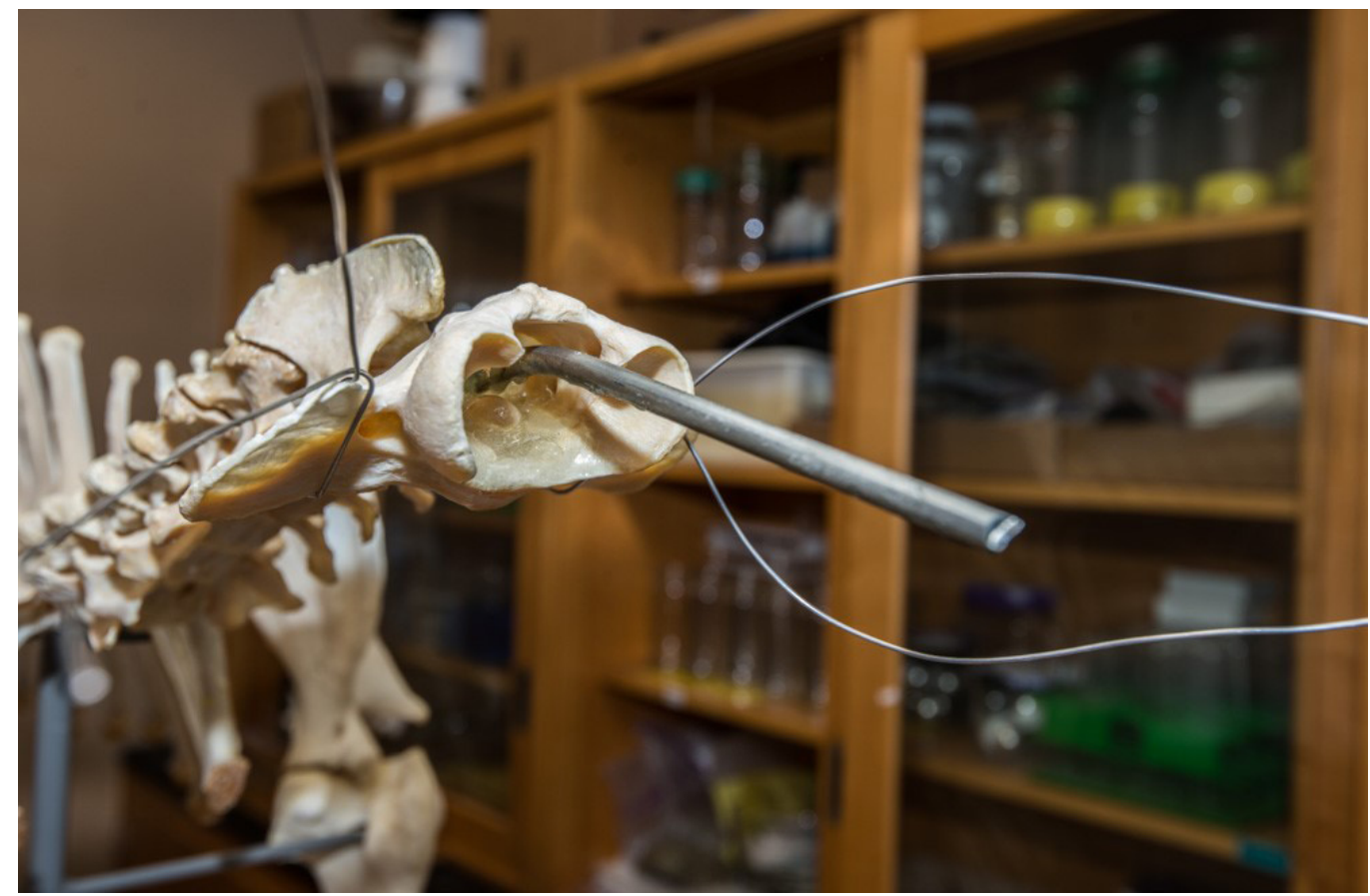

Figure $26-$ Rod and wire preparation prior to mounting the skull. 


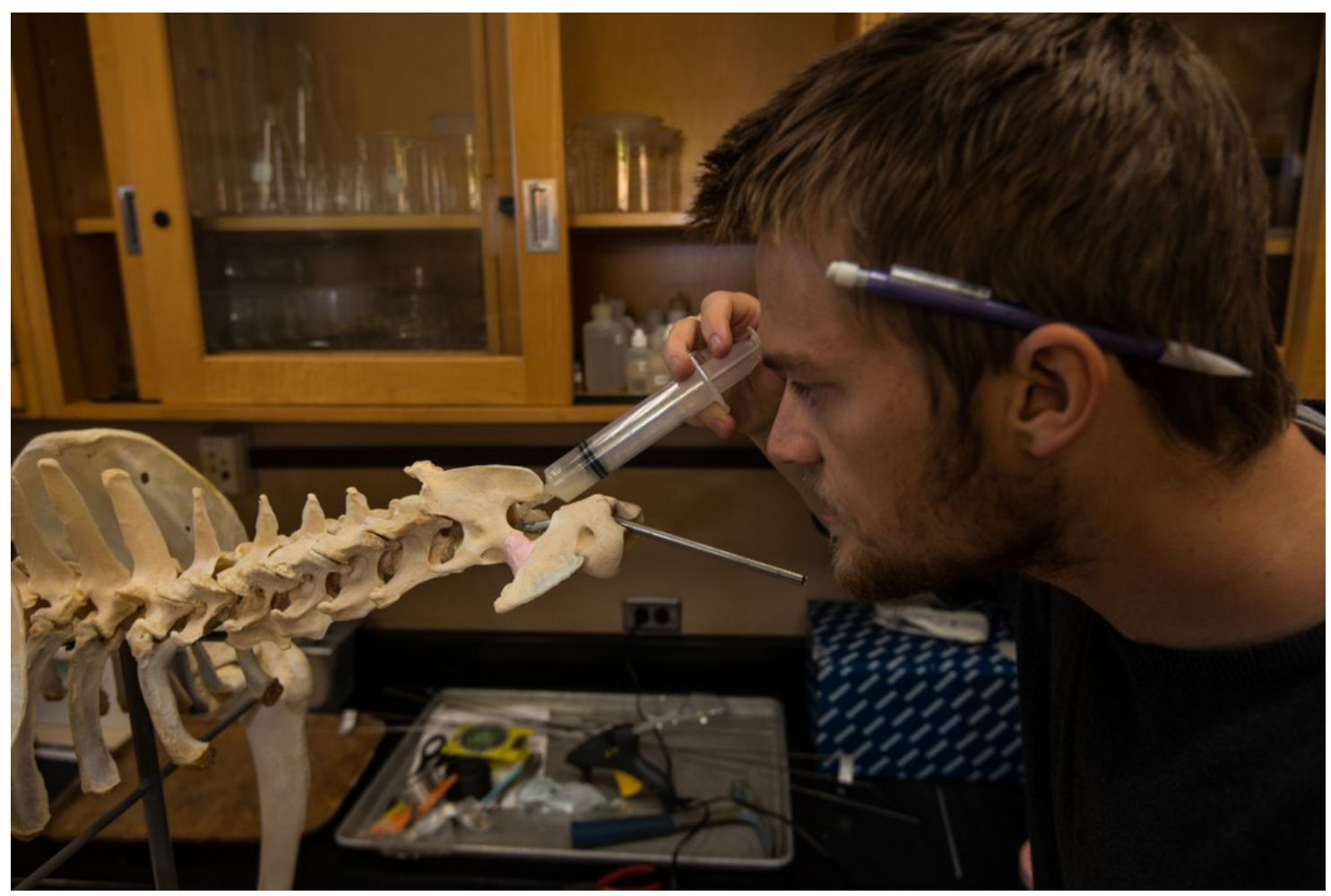

Figure 27-Applying epoxy to the rod and atlas to anchor the attachment.

- Fill the brain case with Devcon epoxy.

- Using a spatula, place a layer of PCII epoxy on the occipital condyles.

o Pay close attention to the drying times of your epoxy and work with appropriate speed.

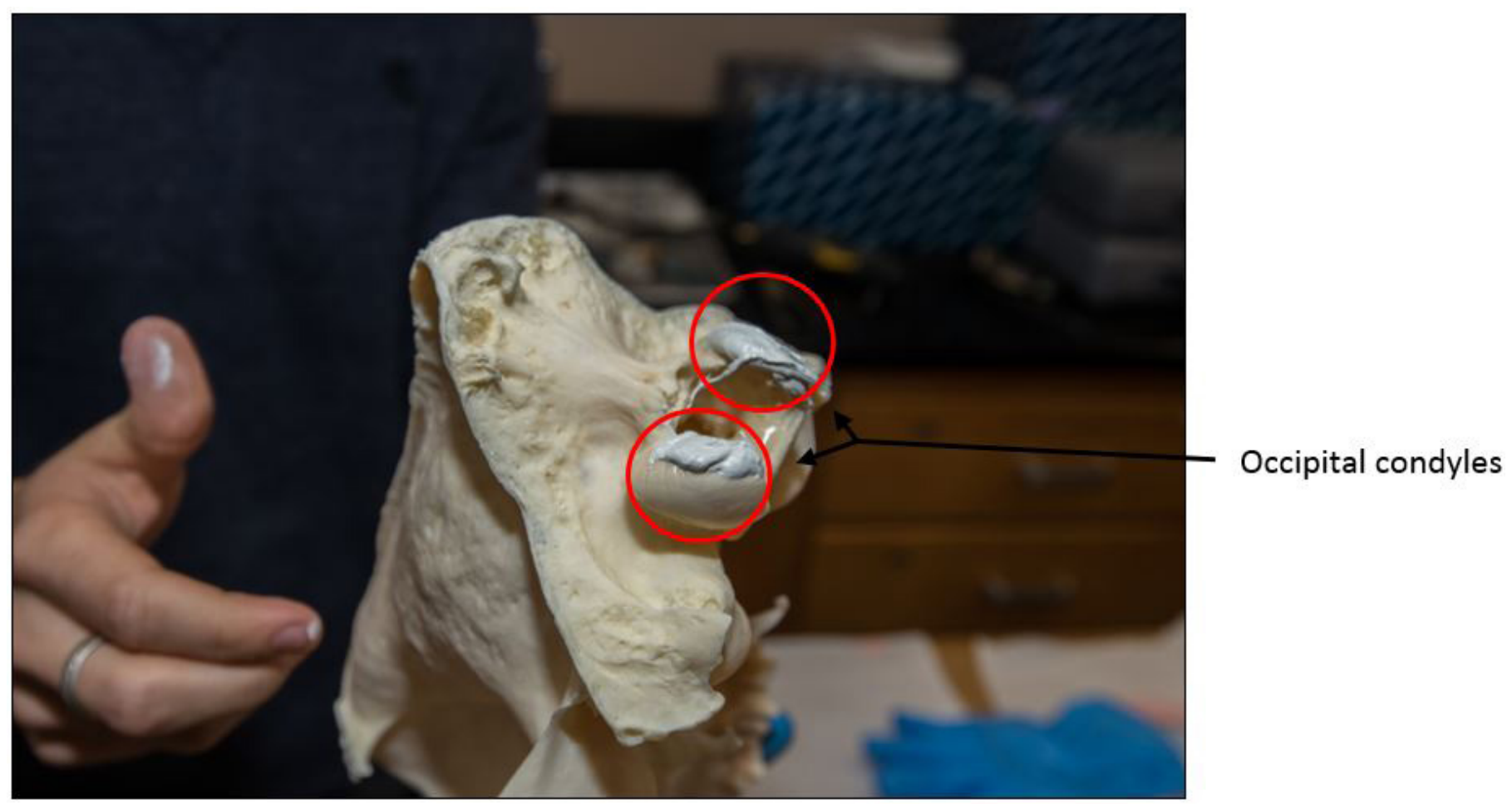

Figure 28-Applying PCII epoxy in preparation for mounting the skull. 
- Mount the skull.

- Tie the steel wire to the zygomatic arch.

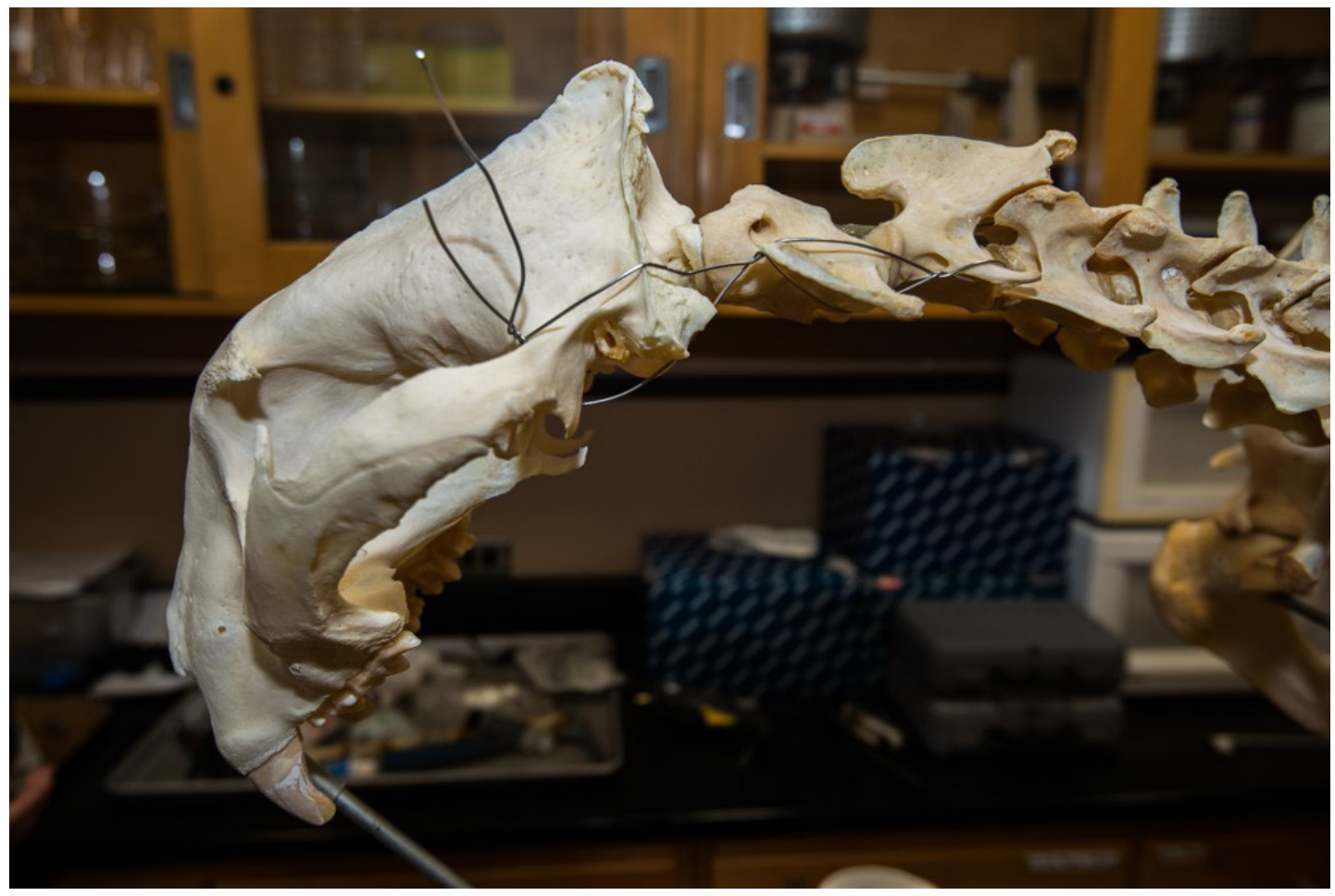

Figure 29-Mounting the skull. Wire is tied from the zygomatic arch to the atlas in order to keep the attachment tight as the epoxy dries. A support rod with a tooth cushion runs from the teeth to the base in order to keep the skull upright at the desired elevation as the epoxy dries.

- Support the weight of the skull with a steel rod running from the tooth to the base.

o Make sure there is a cushion on both ends of the rod to avoid damaging the teeth or base. In this case, we used the end of a centrifuge tube, but paper towels would work as well.

- Add a layer of PCir epoxy to the mandibular condyles on the lower jaw and mount the to the top half of the skull. 


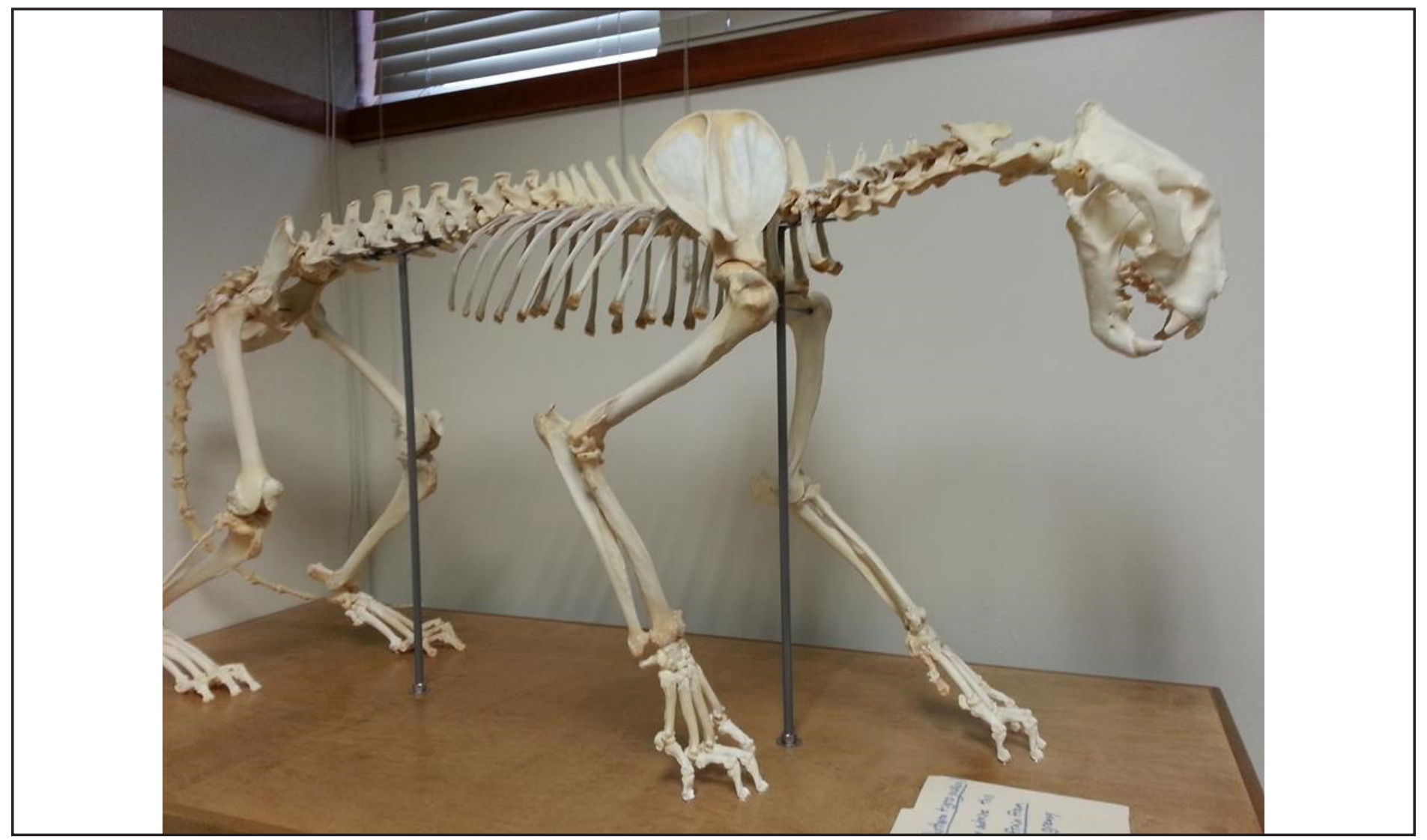

Figure 29 - The final product.

\section{Acknowledgements}

References used to make this protocol include instructions by Ron Ruppert, chair of the Biological Sciences Department at Cuesta College, and Paul Collins, Curator of Vertebrate Zoology at the Natural History Museum in Santa Barbara. This project could not have been done without the help and expertise of bio technicians Dave Clendenen, Mike Stiles, and Doug Brewster, as well as my adviser Dr. John Perrine, a professor at Cal Poly. Credit also goes to the students from the Cal Poly Wildlife Club who spent a long Saturday afternoon assisting in the necropsy and participating in the preliminary cleaning of the skeleton. This project was led in collaboration with two other students as well: Trisha Huynh, Liberal Studies, and Eleisha Bindner, Animal Science. 


\section{Citations}

Ellenberger, Wilhelm (1956). An atlas of animal anatomy for artists. New York: Dover Publications. 